\title{
Externally generated turbulence by a vertically oscillating grid plate and its impact on sediment transport rate
}

Ojha, S. P.; Mazumder, B. S.; Carstensen, S.; Fredsøe, J.

Published in:

Coastal Engineering Journal

Link to article, DOI:

$10.1080 / 21664250.2019 .1619251$

Publication date:

2019

Document Version

Peer reviewed version

Link back to DTU Orbit

Citation (APA):

Ojha, S. P., Mazumder, B. S., Carstensen, S., \& Fredsøe, J. (2019). Externally generated turbulence by a vertically oscillating grid plate and its impact on sediment transport rate. Coastal Engineering Journal, 64(4), 444-459. https://doi.org/10.1080/21664250.2019.1619251

\section{General rights}

Copyright and moral rights for the publications made accessible in the public portal are retained by the authors and/or other copyright owners and it is a condition of accessing publications that users recognise and abide by the legal requirements associated with these rights.

- Users may download and print one copy of any publication from the public portal for the purpose of private study or research.

- You may not further distribute the material or use it for any profit-making activity or commercial gain

- You may freely distribute the URL identifying the publication in the public portal 


\title{
Externally generated turbulence by a vertically oscillating grid plate and its impact on sediment transport rate
}

\author{
S. P. Ojha*+, B. S. Mazumder ${ }^{* *}$, S. Carstensen* and J. Fredsoe*,
}

\begin{abstract}
${ }^{*}$ S. P. Ojha, Scientist, Space Applications Centre (ISRO), Ahmedabad-380015, India. Email: satyaprakash.ojha@gmail.com
\end{abstract}

*** B. S. Mazumder, Emeritus Fellow, Physics and Earth Sciences Division, Fluvial Mechanics Laboratory, Indian Statistical Institute, Calcutta 700 108, India. Phone +91 9831175336, Email: bijoy@isical.ac.in

Present address: Visiting Professor, Department of Civil Engineering, I. I. T., Bombay, India. Email: bsmazumder@gmail.com

${ }^{*}$ S. Carstensen, Associate Professor, Section for Fluid Mechanics, Coastal and Maritime Engineering, Department of Mechanical Engineering, Technical University of Denmark, Nils KoppelsAlle 403, 2800 Kgs, Lyngby, Denmark. Phone +45 $4525 \quad 14$ 02, Email:scar@mek.dtu.dk

*J.Fredsoe, Professor Emeritus, Section for Fluid Mechanics, Coastal and Maritime Engineering, Department of Mechanical Engineering, Technical University of Denmark, Nils KoppelsAlle 403, 2800 Kgs, Lyngby, Denmark.Phone +45 452514 07, Email: jf@mek.dtu.dk

\begin{abstract}
ABSTRAT
The present paper concerns an experimental study of externally generated turbulence and its impact on the bed load sediment transport in an open channel flow. The external turbulence was generated by vertically oscillating a submerged grid, hereafter referred to as turbulence generator, in the flume with a clearance of $11 \mathrm{~cm}$ from the bed. Two kinds of experiments were performed: rigid flat-bed and plane sand-bed. One two dimensional (2-D) LDA was set up to measure the velocity profiles for different values of flow discharge, amplitude and period of oscillations of the turbulence generator. The mean velocities, turbulence intensities, Reynolds shear stress, and their impacts on the rate of sediment transport have been analyzed. The fractional contributions of burst-sweep cycles to the Reynolds shear stress have also been studied. The turbulence generated due to a vertically oscillating submerged grid is an analogous to the production of turbulence beneath the roller located on the front of broken wave, and the impact thus lies on the sediment transport. The Shields parameter was found to be correlated with the sediment transport rate; and the transport rate as a function of turbulence level is found to increase with turbulence level.
\end{abstract}

KEYWORDS: External turbulence; oscillating grid; LDA; turbulence characteristics; sediment transport rate 


\section{Introduction}

The influence of turbulence on sediment transportation and deposition has received much attention in the past. The transportation processes elucidate the highly turbulent nature associated with the turbulent bursting events, and its impact to the sediment movements. Mendoza and Shen(1990) studied numerically the mean and fluctuating components of turbulent flow along two-dimensional dunes. The turbulent field due to flow separation generated by bedforms was also described. Lyn (1993) measured the mean and turbulent characteristics of flows over space-periodic bed form features using two-dimensional Laser Doppler Velocimetry (LDV). The movement of sediment particles takes place due to the presence of excess turbulence generated because of the flow separation at the crests of the bed forms. Nelson et al. (1995a, b) studied the effect of near-bed turbulence on sediment movement in an erodible bed. They showed that sediment movement was a function of nearbed turbulence caused by the flow separation. Several investigations were performed experimentally under controlled conditions in laboratory flumes to study the turbulence and sediment transport over smooth and rough beds. However, these studies were not concerned with the externally generated turbulence and its impact on sediment transport. The pioneering works on the externally generated turbulence by an oscillating grid in water tank were experimentally studied by Thompson and Turner (1975) and Hopfinger and Toly (1976) to estimate the decay law of turbulence and dependence of turbulence parameters on the mesh size, frequency and amplitude of the grid oscillations. Oscillating grid turbulence is often used to address the interfacial mixing in stratified fluids that widely exists in the ocean, the atmosphere and lakes. The idea of grid generated turbulence is used for entrainment across a salinity interface and the initiation of sediment transport at the bed. Brumley and Jirka (1987) generated the bottom-shear-induced turbulence structure in water environment by employing a vertically oscillating grid system, and measured the turbulence using split-film anemometer 
probe. Huppert et al. (1995) performed a series of experiments with an oscillating grid located close to the bottom with sediment bed to simulate the action of stresses acting on the boundary, and compared the results with those obtained using the more extensively studied geometry in which a similar oscillating grid is located in the interior away from the boundary (Turner, 1986; Fernando, 1991). The mechanism of re-suspension of particles depends on the level of turbulence near the bottom boundary below the grid. Subsequently, Lyn (1995) carried out experiments on grid generated turbulence to study the initiation of sediment transport. Cheng and Law (2001) explored the turbulence generated by an oscillating-grid using non-intrusive instrument like Digital Particle Image Velocimetry (DPIV) technique. Eidelman et al. (2002) studied the fully developed turbulence generated from the grid oscillation in a tunnel.

Sumer et al. (2003) described the results of an experimental study on the influence of externally generated turbulence on the bed load transport in an open channel flow. External turbulence was generated by three kinds of turbulence 'generators':- (1) a generator with a horizontal pipe placed with a clearance of $6 \mathrm{~cm}$ from the bed, (2) a generator with a series of grids placed in the flume with a clearance of $6 \mathrm{~cm}$ from the bed, (3) a generator with an extended series of grids placed in the flume with clearance $2-18 \mathrm{~cm}$ from the bed. They used three kinds of generators to obtain the different levels of turbulence in the experiments. The increased turbulence had a profound impact on the sediment transport rate. Medina et al. (2000) and Orlins and Galliver (2003) suggested that sediment transport phenomena such as incipient motion could be studied with grid generated turbulence and give an understanding that could not be realized in open channel flow. The particle-fluid interactions in gridgenerated turbulence were experimentally investigated by Poelma et al (2007). They evaluated systematically the role of particle size, particle density and volume load to study the decay of turbulence. Yan et al. (2007) made an excellent review on the study of 
oscillating grid turbulence and its wide applications in the fields of hydraulic and environmental engineering. Herlina and Jirka (2008) performed experiments on gas transfer mechanism in a grid-stirred tank using a combined particle image velocimetry - laser induced fluorescence (PIV-LIF) technique, which enabled the measurements of two-dimensional velocity and dissolved gas concentration fields. The visualization of the velocity and concentration fields provided direct insight into the gas transfer mechanisms. Kurian and Fransson (2009) revisited the grid-generated turbulence using the energy spectra, turbulence length scales, energy dissipation, kinetic energy decay rate etc. with different mesh and bar widths. Chiapponi et al. (2012) studied the interaction between the turbulence and free surface using vertically oscillating grid moving beneath the free surface. Fluid velocity was measured through a hot-film anemometer, and the free surface elevation was measured by an ultrasonic sensor. Isaza et al. (2014) studied the grid-generated turbulence in the near- and far field regions, where they found that there was a turbulence decay region close to the generating grid that departed from the classical turbulence decay. In the "nearfield' region, the turbulence energy decayed more rapidly than in the far-field and it exhibited unusual scaling properties. In spite of several papers mentioned above were devoted to study the turbulence and sediment transport in the past, little attention has been received with respect to sediment transport associated to the externally generated turbulence by a vertically oscillating grid plate, analogous to what happens under the broken waves, which creates more impact on turbulence and sediment transport. The production of turbulence takes place in the shear layer beneath the 'roller' located on the front of the broken wave (Fig. 1). Moreover, less attention has also been made to investigate the key parameters of turbulence generated from vertically oscillating grid plate, and their impact on sediment transport rate. 


\subsection{Objective of the present investigation}

The purpose of the present investigation is to study experimentally the impact of a vertically oscillating grid. As outlined above, Sumer et al. (2003) investigated two cases of additional external turbulence next to that formed in steady, uniform channel flow: (a) the additional turbulence is caused by a near-bed horizontal cylinder, placed perpendicular to the flow direction. In this case, the additional turbulence was mainly due to the contributions from the downstream vortex shedding behind the cylinder, and (b) turbulence generated behind a number of vertical grids placed a distance above the bed. These two cases demonstrate that the sediment transport increases due to the additional external turbulence. Quantitatively however, this increase strongly depends on the nature of the external turbulence, which can be caused by several reasons such as different structures located in the flow, or by changes in the flow due to non-uniformity and/or unsteadiness.

This investigation has been made to understand the turbulence generated by vertically oscillating grid on the flow and its impact on sediment transport rate in open channel flow. The submerged oscillating grid generates complex fluid flows with jet flows and wakes simultaneously interacting with each other in the flow region. Experiments were conducted for two types of bed surfaces: one is plane rigid-bed and other one is plane sand-bed. One two dimensional (2-D) Laser Doppler Anemometer (LDA) was used to measure the vertical velocity profile over the plane rigid-bed for different values of amplitude and period of oscillations of the grid. The mean velocities, turbulence intensities, Reynolds shear stress, and the fractional contributions of burst-sweep cycles to the Reynolds shear stress have been addressed for various values of amplitude and period of oscillation of the turbulence generator. Moreover, the impacts of turbulence parameters generated by oscillating grid are also analyzed to study the rate of sediment transport. 
The reason for selecting a vertical oscillating plate is to make an analogy to what happens under broken waves: in broken waves, the production of turbulence takes place in the shear layer beneath the 'roller' located on the front of the broken wave (Figure 1), and at a given fixed location the situation is as follows: during the passage of the roller, production of turbulence occur at this location. After the passage of the roller, this production decays, and a break in the production at the location occurs until the next roller reaches the specific location. This signal results in an oscillating variation with time at a specific location, similar to the variation in turbulence level below the broken waves. Such a variation is also obtained by the oscillating grid, where the production of eddies is moved up and down in the fluid, i.e. by varying the distance from the grid to the bed. The bed is hit by a varying strength of turbulence from above.

The motivation for the present investigation is to gain insight in the complicated flow of broken waves and its impact on sediment transport capacity. Deigaard et al. (1986) calculated the turbulence kinetic energy (TKE) beneath a broken wave, and investigated the vertical distribution of sand in broken waves. However the work did not include the impact of surplus turbulence on near-bed sediment transport. The simple turbulence model of Deigaard et al.(1986) predicts a quite fast decay in turbulence intensity towards the bed. This decay is faster than measurements under real broken waves as discussed by Svendsen (1987), based on measurements by Stive and Wind (1982). Because the full picture of the hydrodynamics beneath broken waves is rather complex, it can be discussed what causes this slower observed decrease in TKE towards the bed, and this issue still lacks a full understanding. One way to enlightening this puzzle is the study the different contributions to the production, diffusion and advection of TKE separately to get more detailed insight in the processes. This is the motivation for the present study to focus on only one of the contributions, namely pure vertical diffusion of TKE formed by an oscillatory TKE-signal. 
Waves are breaking in near shore areas, and continue to propagate shoreward very similar to a migrating bore, (Figure 1). In broken waves, the bore - or "surface roller"- produces strong turbulence near the water surface during its migration. This bore moves forward with the wave speed, and has therefore significant larger flow velocity than the wave induced orbital flow beneath, (Deigaard and Fredsoe, 1989). The turbulence is produced in the shear layer between the roller and the flow beneath. From here the turbulence is diffused downward as sketched in Figure 1, and when the bore has passed a specific location, the diffusion at this location will cease, and the turbulence (quantified as TKE) will dissipate (Figure 1). This means that the turbulence level will oscillate around a mean value during the passage of a broken wave. Making a more or less sophisticated analysis of the turbulence in broken waves needs experimental verification, partly regarding the decay in TKE-level towards the bed, and partly on the impact from surface generated turbulence on bed shear stresses and also the resulting near-bed sediment transport. One way to reproduce/simulate this oscillatory variation near the bed can be achieved by moving a horizontal grid vertically up and down at a certain distance away from the bed. This grid will create additional turbulence like in the investigation by Sumer et al. (2003) and in the present case we get a cyclic variation in the near-bed TKE-level.

\section{Experiments}

The experiments were conducted in a $10 \mathrm{~m}$ long, $0.3 \mathrm{~m}$ wide and $0.3 \mathrm{~m}$ deep hydraulic flume at Technical University of Denmark. Water in the flume was recirculated by a pump (Figure 2). The flow rate was controlled by a frequency inverter and monitored using an electromagnetic flow meter. The water depth $h$ was maintained at $0.17 \mathrm{~m}$ for all the tests.

\subsection{Flat rigid-bed experiments}

The flat surface of the flume was made of hydraulically smooth plastic plates, fixed rigidly to the bottom of the flume. Two honeycomb cages, each of one meter length, were placed at the 
upstream end of the flume in order to ensure smooth and vortex free uniform flow of water through the experimental channel. The measurement location was chosen at $6.5 \mathrm{~m}$ downstream from the inlet of the flume, where the flow was fully developed in the undisturbed case. A $0.28 \mathrm{~m}$ wide and $5 \mathrm{~m}$ long 'turbulence generator' made from perforated steel plate was suspended in the flume with a clearance $(e)$ of $0.11 \mathrm{~m}$ from the flat rigid-bed. The perforated steel plate was $1.5 \mathrm{~mm}$ thick with $10 \mathrm{~mm}$ x $10 \mathrm{~mm}$ square holes. The 'turbulence generator' was positioned such that the measurement location was at $4.5 \mathrm{~m}$ downstream from the leading edge of the grid. The porosity of the plate was $70 \%$. A schematic diagram of complete experimental set up with turbulence generator (vertically oscillating grid), test section, sediment trap, honeycombs, false bed and pumping system is illustrated in Figure 2.

Prior to experiments performed for externally generated turbulence, one 2-D LDA was used to record the instantaneous velocity at different vertical positions up to the height $0.17 \mathrm{~m}$ with the stationary submerged perforated plate (undisturbed flow) located at a clearance $(e) 0.11 \mathrm{~m}$ from the bottom at a discharge $Q=10 \mathrm{l} / \mathrm{sec}$. The vertical profiles of mean velocity components $(\bar{u}, \bar{v})$ illustrate the characteristic features of the flow over the rigid-bed surface. Thereafter, the LDA was set up to record the velocity components at different vertical locations above the rigid-bed for different values of flow discharge, period $(T)$ and carriage stroke (CS) of oscillations of the 'turbulence generator'. The velocity data were collected at the sampling rate of $40 \mathrm{~Hz}$ for 6 minutes at each vertical point at the measurement location. Each profile consisted of 10 points from $0.3 \mathrm{~mm}$ up to $10 \mathrm{~mm}$ above the flat surface to ensure the full characterization of the turbulence near the bed. A photograph of the complete experimental set up with 2-D LDA is provided in Figure 3.The carriage stroke is defined as two times the amplitude $(a)$, that is, $\mathrm{CS}=2 a$. Details of parameters from the series of experiments using submerged oscillating grid plate are provided in Table 1. 


\subsection{Plane sediment-bed experiments}

For these experiments, an acrylic sand bed of known grain-size distribution was put in the flume. The grain-size distributions are shown in Figure 4(a) for weight percentage and in Figure 4(b) for cumulative weight percentage. The median particle diameter $\mathrm{d}_{50}$ of the acrylic sand was $0.47 \mathrm{~mm}$ and the standard geometric deviation $\sigma_{\mathrm{g}}\left(=\sqrt{d_{84} / d_{16}}\right)$ was 0.624 . The specific gravity of sediments used for the experiments was 1.13. Experiments were performed over the plane-sand bed surface under exactly the identical flow conditions as previously used in the rigid-bed experiments. In all cases the discharge was so low that no sediment transport was present or bed forms developed without the external turbulence. This allowed the stationary undisturbed flow to be established before the external turbulence was switched on. The external turbulence was switched on until the sand bed in the given test started to form ripples due to the applied external turbulence. This procedure allowed for performing the experiments for $40-100 \mathrm{sec}$ such that it may be assumed that the velocity profile and turbulence statistics apply also in the sediment-bed experiments.

A sediment trap of size $500 \mathrm{~mm}$ long, $300 \mathrm{~mm}$ wide and $50 \mathrm{~mm}$ deep (Figure 2 and Figure 5) was placed in the flume with its leading edge at the location, where the flow velocities were measured in the rigid-bed experiments. The size of the sediment trap was chosen and placed in such a way that eroded sediment particles fall immediately from the sediment bed into the trap; and it was ensured that all eroded particles were deposited in the trap. A photograph of the complete set up of sediment trap together with sediment bed is provided in Figure 5.Sediment transport rates were determined from the deposited sediment in the trap. The sampling time of sediment deposition in the trap varied from 40 to $100 \mathrm{sec}$ depending on the test conditions; and it was as mentioned above determined by the appearance of ripples on the bed (the test was stopped once the sign of the ripples appeared in the bed). Because of the short duration of the tests, it was not possible to measure the flow quantities, i.e., flow 
velocity and the bed shear stress. These were instead inferred from the rigid-bed experiments. Each test was repeated three times to reduce the uncertainty of sediment sample collection in the trap. The deposited sediment in the trap was extracted with help of a suction tube. Attention was made to extract the entire amount of sediment deposited in the trap. After decantation of water from the sediment sample containers, the samples were dried and weighed by an electronic digital scale. Thereafter, the mean values of three samples of extracted sediments from the trap were computed. Flow quantities and the sediment transport rate were also measured for two undisturbed flows, which serve as reference cases. In the following, the mean velocities, turbulence intensities, Reynolds shear stress from the rigidbed experiments and their impacts on the rate of sediment transport are analyzed for various values of oscillation period $(\mathrm{T})$ and amplitude $(\mathrm{a}=\mathrm{CS} / 2)$ of the 'turbulence generator' at different discharges $(\mathrm{Q})$.

\section{Generation of external turbulence and results}

\subsection{Results on turbulence characteristics for rigid-bed experiments}

In the text, $(\bar{u}, \bar{v}, \bar{w})$ and $\left(u^{\prime}, v^{\prime}, w^{\prime}\right)$ denote respectively the time-averaged and the fluctuations of instantaneous velocity components $(u, v, w)$ in the $(x, y, z)$-directions (Figure 2). Here $x$-axis is in the flow direction, $y$-axis is vertical coordinate and $z$-axis is perpendicular to $x y$-plane. For the immobile submerged perforated plate (undisturbed flow), the entire profiles of mean velocities $(\bar{u}, \overline{\mathrm{V}})$ and turbulent intensities $\left(\sqrt{\overline{u^{\prime 2}}}, \sqrt{\overline{v^{\prime 2}}}\right)$ at the centreline against the vertical height of $170 \mathrm{~mm}$ are shown in Figure 6 for a discharge $\mathrm{Q}=10$ 1/sec. It is observed from the figure that the velocity $(\bar{u})$ increases, reaches a maximum value at a level about $\mathrm{y}=40 \mathrm{~mm}$, then reduces up to the level $\mathrm{y}=95 \mathrm{~mm}$; then it shows an irregular variation within the range $95 \leq \mathrm{y} \leq 125 \mathrm{~mm}$ around the submerged grid plate fixed at $\mathrm{y}=110$ 
$\mathrm{mm}$; and there is no variation in velocity for $\mathrm{y}>125 \mathrm{~mm}$ (Fig. 6a). It also shows that the vertical component of velocity $(\bar{v})$ is almost zero throughout the depth except around the level of submerged grid plate. For uniform open channel flow, there should not be significant change from the zero vertical velocity. This anomalous nature of velocities and intensities around the submerged perforated plate may be attributed to wakes and vortices generated from the immobile grids. This has not been investigated further since this is far from the bed and is not expected to influence the results. The intensities of turbulence vary from the bottom boundary up to the level of perforated grid plate with higher values for $u$-component than the $v$-component of intensity.

The normalized velocity profiles for various values of oscillation period and amplitude of the generator are plotted in Figure $7(\mathrm{a}-\mathrm{h})$, where the figures $7(\mathrm{a}, \mathrm{b})$ show the profiles for undisturbed flow cases (Tests $\mathrm{T}_{4}$ and $\left.\mathrm{T}_{14}\right)$. In the following figures, the symbols $\mathrm{T}_{\mathrm{i}}(\mathrm{i}=1,2$, 3..., 17) correspond to the respective tests numbers (Table-1).For the undisturbed cases (Tests $\mathrm{T}_{4}$ and $\mathrm{T}_{14}$, Figure $\left.7 \mathrm{a}, \mathrm{b}\right)$, the normalized stream-wise mean velocity $(\bar{u} / \mathrm{u} *)$ is found to fit well the van Driest (1956) velocity profiles as:

$u^{+}=2 \int_{0}^{y^{+}} \frac{d y^{+}}{1+\left\{1+4 \kappa^{2} y^{+2}\left[1-\exp \left(-y^{+} / A\right)\right]^{2}\right\}^{1 / 2}}$

where $\mathrm{u}^{+}=\left(\bar{u} / u_{*}\right)$ and $\mathrm{y}^{+}=\mathrm{yu} * / v$ are the dimensionless stream-wise velocity and distance respectively. The velocity profile (1) approaches the logarithmic velocity for large $\mathrm{y}^{+}$values and is given by

$\mathrm{u}^{+}=(1 / \kappa) \ln \mathrm{y}^{+}+5$

wherek $(=0.4)$ is the von Karman universal constant. It is observed from Figure $7(a, b)$ that the viscous sub-layer exists for $\mathrm{y}^{+}<5$, buffer layer $\mathrm{y}^{+}<30$, and beyond the logarithmic velocity distribution is approached. The friction velocity $\mathrm{u} *$ is determined from the fitted van 
Driest (1956) profiles (Eq. 1) and the corresponding value of $\mathrm{u} *($ Table-1) is used for normalization of velocity for plotting.

For fixed discharge $(\mathrm{Q}=4.0 \mathrm{l} / \mathrm{s})$ and the time period( $\mathrm{T}=1.0 \mathrm{sec})\left(\mathrm{Tests}_{15}, \mathrm{~T}_{16}, \mathrm{~T}_{17}\right)$, the profiles of stream-wise mean velocity $\left(u^{+}\right)$are respectively shown in Figure 7(c-e) for three different values of carriage stroke $(C S=0.03,0.05,0.07 \mathrm{~m})$; and for fixed $\mathrm{Q}=3.0 \mathrm{l} / \mathrm{s}$ and $\mathrm{CS}$ $=0.03 \mathrm{~m}\left(\right.$ Tests $\left.\mathrm{T}_{8}, \mathrm{~T}_{9}, \mathrm{~T}_{10}\right)$, the mean velocity profiles $\left(u^{+}\right)$are respectively presented in Figure $7(\mathrm{f}-\mathrm{h})$ for different values of time period $(\mathrm{T}=0.5,1.0,2.0 \mathrm{sec})$ of the grid oscillator. It is observed from the figures that for fixed $\mathrm{Q}$ and $\mathrm{T}$, the measured stream-wise velocity increases in the near-bed region up to $y^{+} \approx 30$ for $\mathrm{CS}=0.03$ and $0.05 \mathrm{~m}$ (Figure 7c-d), and beyond the level $y^{+} \approx 30$, the velocity reduces significantly, except for $\mathrm{CS}=0.07 \mathrm{~m}$ (Figure 7e), indicating a strong shear layer generated by the turbulence generator. For fixed $Q=3.0$ 1/s and CS $=0.03 \mathrm{~m}$, similar trends are observed with increase in time period T (Figure $7 \mathrm{f}-\mathrm{h}$ ). Hence for a fixed Q, the velocity changes significantly far from the bed due to externally generated turbulence. Here the van Driest velocity equation (1) is fitted to the measured velocity profiles at the near-bed region for all CS values (Figure 7c-e); and it is observed that Equation (1) fits well only up to the level $y^{+} \approx 30$ for $\mathrm{CS}=0.03$ and $0.05 \mathrm{~m}$ (Figure 7c-d) and it is extended to the level $y^{+} \approx 70$ for $\mathrm{CS}=0.07 \mathrm{~m}$ (Figure $7 \mathrm{e}$ ). These observations are in accordance with those in Sumer et al. (2003). Returning to Figure 7e, here the velocity measurements apparently did not extend far enough to show the strong shear layer generated by the oscillating grid. This is supported by the following observations. For fixed $\mathrm{Q}=4.0 \mathrm{l} / \mathrm{s}$ and $\mathrm{T}=1.0 \mathrm{~s}$ (Figure $7 \mathrm{c}$ ), the stream-wise mean velocity starts to reduce at a certain height about $\mathrm{y}^{+}=25$ for fixed $\mathrm{CS}=0.03 \mathrm{~m}$; and that height of reduction increases with increase in carriage stroke CS (Figure 7c-e). Similar results in the reduction of velocity are also obtained with increase in time period $\mathrm{T}$ for fixed carriage stroke CS. 
The normalized velocity $\left(\bar{u} / u_{*}\right)$ profiles are plotted against vertical coordinate $y$ in Figure $8(\mathrm{a}-$ f) for various values of discharge $(Q)$, carriage stroke $(C S=2 a)$ and period of oscillation $(T)$ of the turbulence generator. From the figure the following qualitative observations can be made. For fixed carriage stroke (CS)and period (T) of the oscillating grid, the velocity $\left(\bar{u} / u_{*}\right)$ increases with increase in flow discharge $(\mathrm{Q})$ shown in Figure 8(a, b); for fixed discharge $\mathrm{Q}$ and time period $\mathrm{T}$, the profiles of mean velocity $\left(\bar{u} / u_{*}\right)$ diverge above the level $\mathrm{y}=0.4 \mathrm{~cm}$, where the larger CS (=2a) generally results in larger mean velocity, as shown in Figure 8(c, d); and for fixed Q and CS, the mean velocity profiles are shown in Figure 8(e, f) for different values of time period $(\mathrm{T})$ of the grid oscillator. Here no significant change in the velocity profiles is observed. Returning to the effect of stroke of the turbulence generator, from Table 1 , tests $\left(T_{5}, T_{6}, T_{7}\right),\left(T_{9}, T_{11}, T_{13}\right)$ and $\left(T_{15}, T_{16}, T_{17}\right)$,it is observed that for fixed flow rate and period of oscillation, the friction velocity $\mathrm{u} *$ decreases with increase in carriage stroke CS. The external turbulence generated due to carriage stroke CS apparently creates resistance to the flow, and hence decrease in $\mathrm{u} *$ due to the formation rollers generated from the oscillating grids. It is also observed that at the largest stroke $\left(\mathrm{CS}=0.07 \mathrm{~m}\right.$, Test $\left.\mathrm{T}_{7}\right)$, the friction velocity $\mathrm{u} *$ is smaller than that of undisturbed flow $\left(\mathrm{T}_{4}\right)$ at $\mathrm{Q}=2.5 \mathrm{l} / \mathrm{s}$, whereas at a lager discharge $\mathrm{Q}$ $=4.0 \mathrm{l} / \mathrm{s}$, the value of $\mathrm{u} *$ shows almost same $\left(\mathrm{T}_{14}, \mathrm{~T}_{17}\right)$. For fixed flow rate and carriage stroke, the friction velocity $\mathrm{u} *$ experiences little to no change with increase in time period $\mathrm{T}$ (Table 1, Tests $\mathrm{T}_{8}$ to $_{10}$ ); which is also valid for other fixed value of carriage strokes CS (Test $\mathrm{T}_{11}$ to $\left._{12}\right)$.

The profiles of normalized turbulence intensities or r.m.s. values for various values of discharge (Q), carriage stroke (CS) and time period (T) of the turbulence generator (Table 1) are plotted against normalized vertical height $\left(y^{+}\right)$in Figure $9(a-c)$ for steam-wise 
$\left(\sqrt{\overline{u^{\prime 2}}} / u_{*}\right)$ intensity, and in Figure $10(\mathrm{a}-\mathrm{c})$ for bottom-normal $\left(\sqrt{\overline{v^{\prime 2}}} / u_{*}\right)$ intensity,including the undisturbed flow (Test $\mathrm{T}_{4}$ ), for reference. The high turbulence intensity is often used as an indicator of the flow potential for erosion and suspension of sediment particles. It is observed that the stream-wise intensity of turbulence $\left(\sqrt{\overline{u^{\prime 2}}} / u_{*}\right)$ decreases with increase of discharge (Q) ranging from $Q=2$ to $41 / \sec$ (Figure 9a, TestsT 2 , $\left.\mathrm{T}_{6}, \mathrm{~T}_{11}, \mathrm{~T}_{16}\right)$ for fixed $\mathrm{CS}=0.05 \mathrm{~m}$ and $\mathrm{T}=1.0 \mathrm{sec}$; it increases with increase in carriage stroke CS (Figure 9b, Tests $\mathrm{T}_{5}, \mathrm{~T}_{6}, \mathrm{~T}_{7}$ )for fixed $\mathrm{Q}=2.5 \mathrm{l} / \mathrm{sec}$ and $\mathrm{T}=1.0 \mathrm{sec}$; and the intensity first decreases, then increases with the time period of oscillations $\mathrm{T}$ (Figure 9c, Tests $\mathrm{T}_{8}, \mathrm{~T}_{9}$, $\mathrm{T}_{10}$ ) for fixed $\mathrm{Q}=3 \mathrm{l} / \mathrm{sec}$ and $\mathrm{CS}=0.05 \mathrm{~m}$. Similar behaviours are also observed for the normalized intensity of turbulence $\left(\sqrt{\overline{v^{\prime 2}}} / u_{*}\right)$ in the bottom-normal direction for same parameter values (Figure 10a, Tests $\mathrm{T}_{2}, \mathrm{~T}_{6}, \mathrm{~T}_{11}, \mathrm{~T}_{16} ;$ Fig.10b, Tests $\mathrm{T}_{5}, \mathrm{~T}_{6}, \mathrm{~T}_{7}$; and Fig. 10c, Tests $\left.\mathrm{T}_{8}, \mathrm{~T}_{9}, \mathrm{~T}_{10}\right)$. Here both the mean intensities show irregular pattern with time period of oscillation $\mathrm{T}$ for fixed discharge $\mathrm{Q}$ and carriage stroke CS (Fig. 9c and 10c). It is observed that stream-wise intensity of turbulence $\left(\sqrt{\overline{u^{\prime 2}}} / u_{*}\right)$ is greater than the bottom-normal intensity $\left(\sqrt{\overline{v^{\prime 2}}} / u_{*}\right)$ for all cases. For comparison, the intensity components $\left(\sqrt{\overline{u^{\prime 2}}} / u_{*}, \sqrt{\overline{v^{\prime 2}}} / u_{*}\right)$ for the undisturbed flow $\left(\right.$ Test $\left.\mathrm{T}_{4}\right)$ are respectively plotted in Figure $9(\mathrm{a}-$ c) and $10(\mathrm{a}-\mathrm{c})$. It is observed that for the undisturbed case (Test $\mathrm{T}_{4}$ ) the turbulence intensity $\left(\sqrt{\overline{u^{\prime 2}}} / u_{*}\right)$ first increases very near the bottom boundary, reaches maximum value, and then decreases with the vertical distance $\mathrm{y}^{+}$from the bed. This trend and the actual values agree 
with those reported by Nezu and Rodi (1986, Figure 12) in the present measuring range extending to a $\mathrm{y}^{+}$level of approximately 40 .

Figure 11 displays the results of normalized Reynolds shear stress component $\left(-\overline{u^{\prime} v^{\prime}} / u_{*}^{2}\right)$ against normalized vertical distance $\mathrm{y}^{+}$for various values of the discharge $(\mathrm{Q})$, the period $(\mathrm{T})$ and the carriage stroke (CS) of the turbulence generator, including the undisturbed flow (Test $\mathrm{T}_{4}$ ), for reference. It is noticed that the Reynolds shear stress $\left(-\overline{u^{\prime} v^{\prime}} / u_{*}^{2}\right)$ decreases with increase in discharge $(\mathrm{Q})$ ranging from 2.5 to $4.0 \mathrm{l} / \mathrm{sec}$ (Figure 11a, Tests $\mathrm{T}_{7}, \mathrm{~T}_{13}, \mathrm{~T}_{17}$ ) for fixed CS $=0.07 \mathrm{~m}$ and $\mathrm{T}=1.0 \mathrm{sec}$. Test $\mathrm{T}_{3}$ is the lowest flow rate combined with the largest stroke $(\mathrm{CS}=0.07 \mathrm{~m})$ of the oscillating grid. Here it is noted that the combination of low flow rate and large stroke of the oscillating grid in test $\mathrm{T}_{3}$ is challenging in respect to measuring accuracy and this is believed to be the reason for test $\mathrm{T}_{3}$ not following the described trend. Furthermore, the Reynolds shear stress increases with CS (Figure 11b, Tests $\mathrm{T}_{5}, \mathrm{~T}_{6}, \mathrm{~T}_{7}$ ) for fixed $\mathrm{Q}=2.5 \mathrm{l} / \mathrm{sec}$ and $\mathrm{T}=1.0 \mathrm{sec}$; and shows irregular pattern with increase in time period $\mathrm{T}$ (Figure 11c, Tests $\mathrm{T}_{8}, \mathrm{~T}_{9}, \mathrm{~T}_{10}$ ) for fixed $\mathrm{Q}=3.0 \mathrm{l} / \mathrm{sec}$ and $\mathrm{CS}=0.03 \mathrm{~m}$. The normalized shear stress in the undisturbed case increases with distance to the bottom boundary, and then levels off in the range $20<\mathrm{y}^{+}<30$. The trend of Reynolds shear stress $\left(-\overline{u^{\prime} v^{\prime}} / u_{*}^{2}\right)$ in the near bed region agrees reasonably well with that of Nezu and Rodi (1986, Figure 3) for the undisturbed case $\left(\mathrm{T}_{4}\right)$.

Figure 12 shows RMS values of fluctuations of Reynolds shear stress $\left(\sqrt{\overline{\tau^{\prime 2}}} / \rho\right)$ against the vertical coordinate $(\mathrm{y})$ for various values of $\mathrm{Q}, \mathrm{T}$ and $\mathrm{a}=\mathrm{CS} / 2$ of the turbulence generator to the flow, where $\tau^{\prime}=u^{\prime} v^{\prime}-\overline{u^{\prime} v^{\prime}}$ is the fluctuating shear stress. The RMS value of fluctuating shear stress $\left(\sqrt{\overline{\tau^{\prime 2}}} / \rho\right)$ decreases with increase in discharge $(\mathrm{Q})$ for fixed CS 
and $\mathrm{T}$ shown in Figure $12 \mathrm{a}\left(\right.$ Tests $\left._{3}, \mathrm{~T}_{7}, \mathrm{~T}_{13}, \mathrm{~T}_{17}\right)$; it increases with increase in CS for fixed $\mathrm{Q}$ and $\mathrm{T}$ shown in Figure $12 \mathrm{~b}$ (Tests $\mathrm{T}_{1}, \mathrm{~T}_{2}, \mathrm{~T}_{3}$ ) and it shows irregular behaviour with $\mathrm{T}$ for both $\mathrm{Q}$ and CS in Figure $12 \mathrm{c}\left(\mathrm{Tests}_{8}, \mathrm{~T}_{9}, \mathrm{~T}_{10}\right)$.

\subsection{Conditional statistics}

The quadrant-analysis is originally devised to sort out the contributions of turbulent events to the Reynolds shear stress $\tau$ from each quadrant of instantaneous values on the $u^{\prime} v^{\prime}-$ plane. The turbulent boundary layer is directly associated with intermittent large-scale coherent structures. These structures are quasi-periodic and they occupy the entire depth of flow, and are characterized randomly by ejection and sweep events. The intermittent contributions to shear stress are associated with these ejection and sweep events. These events characterize the kinematics of structures in the vertical plane. The normalized shear stress $\tau_{\text {dim }}$ is sought to examine the turbulence over the structures with respect to turbulent events. Researchers (Lu and Willmarth, 1973; Clifford et al., 1993; Katul et al., 2006; Ojha and Mazumder, 2008; Mazumder et al., 2009 and Maity and Mazumder, 2014) attempted to determine quantitative results about the structure of Reynolds shear stress from the velocity data, The turbulent events are defined by four quadrants $\left(Q_{i}, i=1,2,3,4\right)$ with outward interaction $\left(i=1, u^{\prime}>\right.$ $\left.0, \mathrm{v}^{\prime}>0\right)$, when high-speed fluid moves far away from the bottom boundary; ejections $(\mathrm{i}=2$, $\mathrm{u}^{\prime}<0, \mathrm{v}^{\prime}>0$ ), for low-speed fluid moving far away from the bottom boundary; inward interactions $\left(\mathrm{i}=3, \mathrm{u}^{\prime}<0, \mathrm{v}^{\prime}<0\right)$, for low-speed fluid moving towards the bottom boundary; and sweeps ( $\left.\mathrm{i}=4, \mathrm{u}^{\prime}>0, \mathrm{v}^{\prime}<0\right)$, occurring when high-speed fluid moves toward the bottom boundary (Nakagawa and Nezu, 1977).The quadrant technique and the conditional averaged method are used to examine the characteristics of bursting events. The ejection is a sudden outward motion of low-speed fluid from the bottom boundary associated with the values of $\mathrm{u}^{\prime} \mathrm{v}^{\prime}$ in the second quadrant $\left(\mathrm{u}^{\prime}<0, \mathrm{v}^{\prime}>0\right)$. Similarly, a sweep phase is the motion of high- 
speed fluid moving toward bottom boundary associated with the amplitude values of $u^{\prime} v^{\prime}$ in the fourth quadrant $\left(\mathrm{u}^{\prime}>0, \mathrm{v}^{\prime}<0\right)$. Two dimensional quadrant analyses are performed to study the effects of different events on the Reynolds shear stress for various values of flow discharge $(Q)$, and period of oscillation $(T)$ and carriage stroke $(C S=2 a)$ of the turbulence generator. At any point in a steady flow, the contributions of the turbulent events to the Reynolds shear stress from quadrant $i$, excluding a hyperbolic hole region $H$, is given by

$$
\left\langle u^{\prime} v^{\prime}\right\rangle_{i, H}=\lim _{T \rightarrow \infty} \int_{0}^{T} u^{\prime}(t) \mathrm{v}^{\prime}(t) I_{i, H}\left[u^{\prime}(t), \mathrm{v}^{\prime}(t)\right] d t
$$

where square brackets denote a conditional average and the indicator function $I_{i, H}$ is defined as

$I_{i, H}\left(u^{\prime} v^{\prime}\right)=\left\{\begin{array}{l}1, \text { if }\left(u^{\prime} v^{\prime}\right) \text { is in the ith quadrant and }\left|u^{\prime} v^{\prime}\right| \geq H\left|\overline{u^{\prime} v^{\prime}}\right| \\ 0, \text { otherwise }\end{array}\right.$

The parameter $\mathrm{H}$ is a threshold level in the Reynolds stress signals. The contributions to each quadrant of the extreme value of shear stress were determined (Nezu and Nakagawa, 1993; Clifford et al., 1993). Here the stress fraction is given by

$$
S_{i, H}=\frac{\left\langle u^{\prime} v^{\prime}\right\rangle_{i, H}}{\overline{u^{\prime} v^{\prime}}}
$$

By definition, $S_{i, H}>0$ if $\mathrm{i}$ is even (ejections and sweeps) and $S_{i, H}<0$ if $\mathrm{i}$ is odd (outward and inward interactions). Moreover, $S_{1,0}+S_{2,0}+S_{3,0}+S_{4,0}=1$ for threshold level (hole size) $\mathrm{H}=0$. For a fixed discharge $Q=3 \mathrm{l} / \mathrm{sec}$, the contributions of stress fraction $\left|S_{i, H}\right|$ to the Reynolds shear stress for all four quadrant events are plotted against the threshold parameter $H$ in Figure 13a for $\mathrm{y}=0.3 \mathrm{~cm}, C S=3 \mathrm{~cm}$ and $T=1$, and $2 \mathrm{sec}\left(\right.$ Tests $\mathrm{T}_{9}$ and $\mathrm{T}_{10}$ ); in Figure $13 \mathrm{~b}$ for $\mathrm{y}=0.15 \mathrm{~cm}, T=1 \mathrm{sec}$ and $C S=3,5 \mathrm{~cm}$ (Tests $\left.\mathrm{T}_{9}, \mathrm{~T}_{11}\right)$; and in Figure $13 \mathrm{c}$ for $\mathrm{T}=1 \mathrm{sec}$, $\mathrm{CS}=5 \mathrm{~cm}\left(\right.$ Test $\left.\mathrm{T}_{11}\right)$ and $\mathrm{y}=0.15,1.0 \mathrm{~cm}$. The overall trend of these figures shows that the contributions of ejections and sweeps $\left(Q_{2}\right.$ and $\left.\mathrm{Q}_{4}\right)$ to the shear stress $\left|\mathrm{S}_{\mathrm{i}, \mathrm{H}}\right|$ are much higher 
than that of the outward and inward interactions $\left(\mathrm{Q}_{1}\right.$ and $\left.\mathrm{Q}_{3}\right)$ for any hole size $\mathrm{H}$ for all these parameter values (Figure 13). The intensities of stress fraction $\left|S_{i, H}\right|$ for all events decrease with increasing the vertical distance from the near-wall, that agree reasonably well with Fer et al. (2004). This increment near the boundary is probably linked with relatively high turbulence level. For example, at the bottom level $\mathrm{y}=0.15 \mathrm{~cm}$ for threshold parameter $H=2$, period of oscillation $T=1 \mathrm{sec}$, carriage stroke $C S=5 \mathrm{~cm}$ (Test $\left.T_{11}\right)$, the contributions of stress fraction from all the quadrants are $S_{1,2}=-0.06, S_{2,2}=0.47, S_{3,2}=-0.04, S_{4,2}=0.49$; the sum of which is 0.86 , i.e., $86 \%$ of average shear stress $\tau$, and at the higher level $\mathrm{y}=1.0 \mathrm{~cm}$, sum of contributions from the quadrants is $10 \%$ of average shear stress. It implies that the sum of contributions of all quadrant events decreases from the bottom level to height $\mathrm{y}=1.0 \mathrm{~cm}$ for threshold parameter $H>0$ (Figure 13c).For fixed value of $\mathrm{y}=0.3 \mathrm{~cm}, \mathrm{CS}=3 \mathrm{~cm}$ at $\mathrm{H}=2$; the contributions from the quadrants are $S_{1,2}=-0.64, S_{2,2}=0.98, S_{3,2}=-0.54, S_{4,2}=0.97$; the sum of which is 0.77 , i.e., $77 \%$ of average shear stress $\tau$ for period of oscillation $\mathrm{T}=1 \mathrm{sec}$. (Test $\mathrm{T}_{9}$ ), and the $88 \%$ of average shear stress $\tau$ is for $\mathrm{T}=2 \sec \left(\right.$ Test $\mathrm{T}_{10}$ ) (Figure 13a).For fixed level $\mathrm{y}=0.15 \mathrm{~cm}, \mathrm{~T}=1 \mathrm{sec}$, the contributions from the quadrant events are $\mathrm{S}_{1,2}=-0.47, \mathrm{~S}_{2,2}$ $=0.97, \mathrm{~S}_{3,2}=-0.52, \mathrm{~S}_{4,2}=0.99$; the sum of which is 0.97 , i.e., $97 \%$ of the average shear stress for carriage stroke $\mathrm{CS}=3 \mathrm{~cm}\left(\right.$ Test $\left.\mathrm{T}_{9}\right)$; and the $86 \%$ of average shear stress $\tau$ is for $\mathrm{CS}=$ $5 \mathrm{~cm}\left(\right.$ Test $\left.\mathrm{T}_{11}\right)$ (Figure 13b).

\subsection{Results for the sand-bed experiments}

Sand-bed experiments are carried out for the undisturbed flow (Tests $\mathrm{T}_{4}, \mathrm{~T}_{14}$ in Table1), which are the reference cases for the present experiments. Deposited sediment materials collected from the sediment trap are analyzed for size distribution. Percentage and cumulative percentage plots of grain-size distributions of the deposited materials for the Test $\mathrm{T}_{14}$ are shown respectively in Figure 14(a, b). Table-1 presents the test conditions and the results of 
the plane rigid-bed as well as the sand-bed experiments. Altogether 17 test runs are considered. In the table, $U$ is the cross-sectional mean velocity $(U=Q / A)$, where A is the cross-sectional area $(A=170 \mathrm{~mm} \times 300 \mathrm{~mm}), q$ is the rate of bed load transported in volume per unit time per unit width, and $q_{u}$ is the rate of bed load transported for the undisturbed flow conditions. The sediment transport rate for tests $\left(T_{15}, T_{16}, T_{17}\right)$ is normalized by that measured in the undisturbed case $q_{u}$, while the turbulence level is normalized by the mean value of the bed shear stress $\bar{\tau}$. The $q_{u}$ has been measured to be $q_{u}=0.011 \times 10^{-2} \mathrm{~cm}^{3} / \mathrm{cm} . \mathrm{s}$ for undisturbed flow (Test $\mathrm{T}_{14}$, column 13). Figure 15 displays the sediment transport rate $q / q_{u}$ normalized by undisturbed transport rate $\mathrm{q}_{\mathrm{u}}$ against the turbulence level $\left(\sqrt{\overline{\tau^{\prime 2}}} / \bar{\tau}\right)_{y=0}$ measured for different values of $C S$ with fixed $Q$ and $T$, indicated by the tests $\mathrm{T}_{15}, \mathrm{~T}_{16}$, and $\mathrm{T}_{17}$. No clear trend is observed in the normalized sediment transport rate $q / q_{u}$ as a function of the turbulence level $\left(\sqrt{\overline{\tau^{\prime 2}}} / \bar{\tau}\right)_{y=0}$ although the table shows a significant increase in the sediment transport with increasing carriage stroke CS.

Assuming $\theta_{b}$ be the Shield parameter as:

$\theta_{b}=\frac{u_{*}^{2}}{g(s-1) d_{50}}$

in which $u *=\tau / \rho=$ friction velocity, $\tau$ is the shear stress, $\rho$ is the density of water and $g$ is the acceleration due to gravity. The quantity $\theta_{c r}$ is the critical value of the Shield parameter corresponding to the initiation of motion of the particle at the bed. The grain Reynolds number $\left(R_{f}=u * d_{50} / v\right)$ was always kept below 5 (Table 1) ensuring that the bed in the 
sediment transport experiments acted as a hydraulically smooth boundary. Therefore, the bed shear stress in the case of sediment bed will be the identical as that measured in the case of rigid-bed experiments. The parameter $\phi_{b}$ is the dimensionless form of the bed load discharge and is defined as

$$
\phi_{b}=\frac{q}{\sqrt{g(s-1) d_{50}^{3}}}
$$

The values of $\phi_{b}$ and corresponding $\theta_{b}$ are presented in respective columns 16 and 15 in Table-1 for various test runs. Figure 16 shows the plots of dimensionless Shields parameter $\theta_{b}$ versus dimensionless bed load discharge $\phi_{b}$ for different ranges of $\left(\sqrt{\overline{\tau^{\prime 2}}} / \bar{\tau}\right)_{y=0}$ for all the test runs $\mathrm{T}_{2}, \mathrm{~T}_{3}, \mathrm{~T}_{4}, \mathrm{~T}_{5}, \ldots \ldots ., \mathrm{T}_{17}$. The tests $\mathrm{T}_{4}(Q=2.51 / \mathrm{s})$ and $\mathrm{T}_{14}(Q=4.01 / \mathrm{s})$ represent the undisturbed experiments. As there were no sediment transport in $\mathrm{T}_{4}$, only the data of $\mathrm{T}_{14}$ for undisturbed experiment are presented, which is reasonable as reported by Sumer et al (2003). The line indicated by $M$ in Figure 16 is drawn from the formula of Meyer-Peter and Muller (1948) with $\theta_{c r}=0.05$ (See Sumer et al. 2003). For runs $\mathrm{T}_{15}, \mathrm{~T}_{16}$ and $\mathrm{T}_{17}$, the bed load discharge $\phi_{b}$ increases with carriage stroke CS. The similar result is observed for runs $\mathrm{T}_{5}$ to $\mathrm{T}_{7}$. For runs $\mathrm{T}_{8}, \mathrm{~T}_{9}$ and $\mathrm{T}_{10}$, the value of $\phi_{b}$ show minor change (perhaps with a small reduction) with increasing period $\mathrm{T}$. Finally for runs $\mathrm{T}_{3}, \mathrm{~T}_{7}, \mathrm{~T}_{13}$ and $\mathrm{T}_{17}$, no change in $\phi_{b}$ is observed with increase in discharge $Q$ for fixed $\mathrm{CS}=0.07 \mathrm{~m}$ and period $\mathrm{T}=1.0 \mathrm{~s}$. Similar result is also observed for runs $\mathrm{T}_{2}$ and $\mathrm{T}_{6}$ for fixed $\mathrm{CS}=0.05 \mathrm{~m}$ and $\mathrm{T}=1.0 \mathrm{~s}$. Overall the figure indicates that for a given value of $\theta_{b}$, the sediment transport rate increases with an increase of $\left(\sqrt{\overline{\tau^{\prime 2}}} / \bar{\tau}\right)_{y=0}$ for different test runs. 


\section{Conclusions}

The purpose of the present study was to ascertain the relative influence of externally generated turbulence using vertically oscillating grid plate to the sediment transport rate. The turbulence generated from the oscillating grid plate is analogous to what happens under the broken waves, which produces turbulence in the shear layer beneath the roller on the front of the broken wave (Figure 1). In the plane rigid-bed experiments, the stream-wise mean velocity profiles for the undisturbed flow match quite well with that of van Driest (1956), whereas the velocity profiles generated by the external turbulence begin to deviate from the van Driest at the distance $y^{+}=25$ from the bottom (Figure 7). The deviation of velocity profiles arises due to the wakes generated from the submerged grid oscillator. At the plane surface for the undisturbed flow, the qualitative behaviour of RMS values of turbulence and shear stress agrees reasonably well with Nezu and Rodi (1986) near boundary region, whereas for the externally generated turbulent flow, the RMS values of turbulence and shear stress change significantly. It is interesting to note that the overall trend of the contributions of ejections and sweeps $\left(Q_{2}\right.$ and $\left.Q_{4}\right)$ to the shear stress $\left|S_{i, H}\right|$ are much higher than that of the outward and inward interactions $\left(Q_{1}\right.$ and $\left.Q_{3}\right)$ for any hole size $H$ for all the parameter values. In the plane sand-bed experiments, we repeated the series of experiments under exactly the identical flow conditions to study the bed load transport. The bed shear stress in the case of sediment bed was maintained same as that of rigid-bed experiments. The normalized sediment transport rate $q / q_{u}$ as a function of turbulence level $\left(\sqrt{\overline{\tau^{\prime 2}}} / \bar{\tau}\right)_{y=0}$ increases with increase in carriage stroke CS. For a given value of $\theta_{b}$, the sediment transport rate $\phi_{b}$ increases with an increase in $\left(\sqrt{\overline{\tau^{\prime 2}}} / \bar{\tau}\right)_{y=0}$ and it increases significantly from the undisturbed flow. 


\section{Acknowledgements}

One of the authors (BSM) would like to express his sincere thanks to Professors Jorgen Fredsoe and B. M. Sumer for their financial support to carry out this research at the Technical University of Denmark, MEK, Coastal and River Engineering Section. We express our sincere thanks to Professor Sumer for his important contributions through discussion during the preparation of the paper. We must acknowledge Dr. Krishnendu Barman for his help in drawing the quadrant analysis figures.

\section{Notations:}

$\mathrm{A}=$ Cross-sectional area;

$\mathrm{a}=$ amplitude of turbulence generator;

$\mathrm{d}_{50}=$ median diameter of sediment particles;

$\mathrm{e}=$ clearance from the edge of turbulence generator to the bed;

$\mathrm{g}=$ acceleration due to gravity;

$h=$ flow depth;

$H=$ threshold level (hole size);

$M=$ line indicates Meyer-Peter and Muller (1948);

$Q=$ flow rate;

$q=$ measured bed load sediment transport rate (sediment trap method);

$\mathrm{q}_{\mathrm{u}}=$ measured bed load sediment transport rate for undisturbed condition (sediment trap

method, plane-bed experiments only);

$R_{f}=$ grain Reynolds number $\left(\mathrm{R}_{\mathrm{f}}=\mathrm{u} * \mathrm{~d}_{50} / v\right)$;

$\mathrm{s}=$ relative density;

$S_{i H}=$ stress fraction at ith quadrant;

$T=$ wave period of turbulence generator;

$\mathrm{T}_{\mathrm{i}}=$ test runs for $\mathrm{i}=1,2,3, \ldots . .17$.

$u, v, w=$ instantaneous velocity components;

$(\bar{u}, \bar{v}, \bar{w})=$ mean velocity components

$\left(u^{\prime}, v^{\prime}, w^{\prime}\right)=$ fluctuating components of velocity;

$\mathrm{u} *=$ friction velocity;

$\mathrm{u}^{+}=$dimensionless velocity;

$\mathrm{y}=$ distance from the bed;

$\mathrm{y}^{+}=$dimensionless distance from the bed; 
$\theta_{\mathrm{b}}=$ Shields parameter corresponding to bed friction velocity;

$v=$ kinematic viscosity;

$\rho=$ density of fluid;

$\sigma_{\mathrm{g}}=$ geometric standard deviation $\left(=\sqrt{\frac{d_{84} / d_{16}}{}}\right)$;

$\tau=$ instantaneous shear stress;

$\tau^{\prime}=$ fluctuating shear stress;

$\phi_{b}=$ dimensionless bed load discharge.

\section{References}

Brumley, B.H. and G. H. Jirka. 1987.“Near-surface turbulence in a grid-stirred tank”. J. Fluid Mech.183, 236-263.

Cheng, N.S., and A. W. K. Law. 2001."Measurement of turbulence generated by oscillating grid".Journal of Hydraulic Engineering, 127(3), 201-208.

Chiapponi, L., S. Longo,and M. Tonelli. 2012. "Experimental study on oscillating grid turbulence and free surface fluctuation”. Experiments in Fluids, 53(5), 1515-1531.

Clifford, N.J., J. R. French, and J. Hardisty. 1993. "Turbulence: Perspective on flow and sediment transport”. John Wiley \& Sons: Chichester.

Deigaard, R., J. Fredsøe, and I. B. Hedegaard. 1986. "Suspended sediment in the surf zone". Journal of Waterway, Port, Coastal, and Ocean Engineering 112 (1), 115-128.

Deigaard, R., and J. Fredsoe. 1989. "Shear stress distribution in dissipative water waves".Coastal Engineering, 13(4), 357-378.

Eidelman, A., T. Elperin, A. Kapusta, N. Kleeorin, A. Krein, and I. Rogachevskii.2002. "Oscillating grids turbulence generator for turbulent transport studies". Nonlinear Processes in Geophysics, 9: 201-205.

Fer, I., M. G. McPhee, and A. Sirevaag2004. "Conditional statistics of theReynolds stress in the under-ice boundary layer". J. Geophysical Res.31, L15311. DOI: 10.1029/2004GL020475.

Fernando, H.J.S.1991. "Turbulent mixing in stratified fluids". Ann. Rev. Fluid Mech.23, 455493.

Herlina, and G. H. Jirka. 2008. "Experiments on gas transfer at the air-water interfaceinduced by oscillating grid turbulence". Journal of Fluid Mechanics, 594, 183-208.

Hopfinger, E.J., and J. A. Toly. 1976. "Spatially decaying turbulence and its relation to mixing across density interfaces". J. Fluid Mech. 78, 155-175. 
Huppert, H. E., J. S. Turner,and M. A. Hallworth. 1995. "Sedimentation and entrainment in dense layers of suspended particles stirred by an oscillating grid", J. Fluid Mech.289, 263293.

Isaza, J.C., R. Salazar, and Z. Warhaft. 2014. "On grid-generated turbulence in the near- and far field regions”, Journal of Fluid Mechanics, 753, 402- 426.

Katul, G.,D. Poggi, D. Cava, D.,and J. Finnigan. 2006. "The relative importance of ejections and sweeps to momentum transfer in the atmospheric boundary layer". Boundary-Layer Meteorology 120(3): 367-375.

Kurian, T., and J. H. M. Fransson, 2009. "Grid-generated turbulence revisited", Fluid Dynamics Research, Volume 41, Number 2.

Lyn, D.A., 1993“Turbulence measurements in open-channel flow over artificial bed forms". J. Hydraul. Engineering, 119(3), 306-325.

Lyn, D.A.1995. "Observations of initial sediment motion in a turbulent flow generated in a

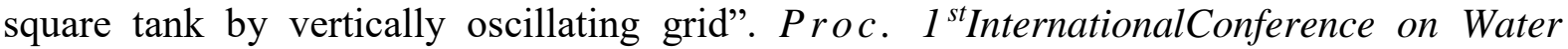
Resources. ASCE, New York. Vol.1, 608-612.

Lu, S.S., and W. W. Willmarth. 1973."Measurements of the structures of the Reynolds stress in a turbulent boundary layer". Journal of Fluid Mechanics, 60: 481-511.

Maity H. and B. S. Mazumder. 2014. "Experimental investigation of the impacts of coherent flow structures upon turbulence properties in regions of crescentic scour". Earth Surface Processes and Landforms-Wiley, 39 (8): 995-1013. DOI: 10.1002/ ESP3496.

Mazumder, B.S., D. K. Pal, K. Ghoshal, and S. P. Ojha. 2009. "Turbulence statistics of flow over isolated scalene and isosceles triangular-shaped bedforms". Journal of Hydraulic Research, IAHR 47(5): 626-637.

Medina, P., M. A. Sanchez, and J. M. Redondo. 2000.“Grid stirred turbulence: applications to the initiation of sediment motion and lift-off studies". Physics and Chemistry of the Earth, 26(4), 299-304.

Mendoza, C., and H. W. Shen. 1990. "Investigation of turbulent flow over dunes".J. Hydraul. Engineering, 116(4), 459-477.

Meyer-Peter, E., and R. Muller. 1948. "Formula for bed-load transport". Proc. Int. Association for Hydraulic Structures Research, $2^{\text {nd }}$ Meeting, Oskar Eklunds Boktryckeri, Stockholm, Sweden, 39-64.

Nakagawa H.,and I. Nezu. 1977. "Prediction of the contributions to the Reynolds stress from bursting events in open-channel flows". Journal of Fluid Mechanics. 80(1), 99-128.

Nelson, J.M., R. L. Shreve, and S. R. McLean. 1995a. "Role of near-bed turbulence in bedload transport".Proc. $10^{\text {th }}$ Conf. on Engineering Mechanics. ASCE, New York,686-689.

Nelson, J.M., R. L. Shreve, S. R. McLean, and T. G. Drake. 1995b. "Role of nearbedturbulence in bed load transport and bed form mechanics".Water Resour. Res., 31(8),2071-2085. 
Nezu, I.,and H. Nakagawa. 1993. “Turbulence in Open Channel Flows”, IAHR Monograph. Balkema: Rotterdam.

Nezu, I., and W. Rodi. 1986. "Open-channel flow measurements with laser Doppler anemometer”.J. Hydraul. Engineering, 112(5), 335-355.

Orlins, J.J., and J. S. Gulliver. 2003. "Turbulence quantification and sediment resuspensionin oscillating grid chamber". Exp. Fluids34, 662-677.

Ojha, S. P., and B. S. Mazumder. 2008. "Turbulence characteristics of flow region over a seriesof 2-D dune shaped structures. Adv Water Res, 31:561-76.

Poelma, C., J. Westerwell, and G. Ooms. 2007. "Particle-fluid interactions in grid-generated turbulence", Journal of Fluid Mechanics, 589, 315-351.

Stive, M. J. F., and H. G. Wind. 1982. "A study of radiation stress and set-up in the nearshore region". Coastal Eng., 6, 1-25.

Sumer, B.M., L. H. C. Chua, N. S. Cheng, and J. Fredsoe. 2003. "Influence of turbulence onbed load sediment transport”. J. Hydraulic Engineering, 129(8), 585-596.

Svendsen, I.A. 1987."Discussion of "Suspended Sediment in the Surf Zone" by Rolf Deigaard, JørgenFredsøe, and Ida BrøkerHedegaard (January, 1986, Vol. 112, No. 1)”. Journal of Waterway, Port, Coastal, and Ocean Engineering, 113 (5), 555 - 557.

Thompson, M., and J. S. Turner. 1975. "Mixing across an interface due to turbulence generated by an oscillating grid". J. Fluid Mech.67, 349-368.

Turner, J.S.1986. "Turbulent entrainment: the development of the entrainment assumption and its application to geophysical flows". J. Fluid Mech.173, 431-471.

van Driest, E.R. 1956. “On turbulent flow near a wall”. J. Aeronaut. Sci., 23, 1007-1011.

Yan, J., N. S. Chang, H. Tang, and S. K. Tan. 2007. "Oscillating-grid turbulence and its applications: a review". Journal of Hydraulic Research 45(1), 26-32. 
Table1. Details of the parameters generated from the experiments with or without disturbance.

\begin{tabular}{|c|c|c|c|c|c|c|c|c|c|c|c|c|c|c|c|}
\hline $\begin{array}{l}\text { Test } \\
\text { No. } \\
\left(T_{i}\right) \\
\end{array}$ & $\begin{array}{l}\text { Turbulence } \\
\text { Generator }\end{array}$ & $\begin{array}{l}Q \\
(1 / \mathrm{s})\end{array}$ & $\begin{array}{l}U \\
=\mathrm{Q} / \mathrm{A} \\
(\mathrm{cm} / \mathrm{s})\end{array}$ & $\begin{array}{l}\text { Temp } \\
{ }^{\circ} \mathrm{C}\end{array}$ & $\begin{array}{l}\text { Carriage } \\
\text { stroke } \\
\text { CS (m) }\end{array}$ & $\begin{array}{l}\text { Period } \\
\mathrm{T}(\mathrm{sec})\end{array}$ & $\begin{array}{l}u_{*} \\
(\mathrm{~cm} / \mathrm{s})\end{array}$ & $\begin{array}{l}\tau / \rho \\
\mathrm{cm}^{2} / \mathrm{s}^{2}\end{array}$ & $\left(\sqrt{\tau^{\prime 2}}\right)_{0}$ & $\left(\sqrt{ } \tau^{2} / \tau\right)_{0}$ & $\left(u * d_{50}\right) / v$ & $\begin{array}{l}q \\
\left(\mathrm{~cm}^{2} / \mathrm{s}\right)\end{array}$ & $q / q_{u}$ & $\theta_{b}$ & $\phi_{b}$ \\
\hline 1 & Grid plate & 2.0 & 3.92 & 24.2 & 0.03 & 1.0 & ----- & ---- & 0 & ---- & ---- & $0.004 \times 10^{-2}$ & --- & --- & --- \\
\hline 2 & Grid plate & 2.0 & 3.92 & 24.1 & 0.05 & 1.0 & 0.35 & 0.12 & 0.0219 & 0.1794 & 1.60 & $0.042 \times 10^{-2}$ & --- & 0.0204 & 0.0036 \\
\hline 3 & Grid plate & 2.0 & 3.92 & 23.5 & 0.07 & 1.0 & 0.35 & 0.12 & 0.1966 & 1.6095 & 1.60 & $0.298 \times 10^{-2}$ & --- & 0.0204 & 0.0259 \\
\hline 4 & Undisturbed & 2.5 & 4.90 & 24.4 & 0.0 & 0.0 & 0.37 & 0.14 & 0.0167 & 0.122 & 1.74 & --- & --- & 0.0228 & --- \\
\hline 5 & Grid plate & 2.5 & 4.90 & 24.6 & 0.03 & 1.0 & 0.45 & 0.20 & 0.0215 & 0.1063 & 2.11 & $0.021 \times 10^{-2}$ & --- & 0.0338 & 0.0018 \\
\hline 6 & Grid plate & 2.5 & 4.90 & 24.5 & 0.05 & 1.0 & 0.43 & 0.18 & 0.0585 & 0.3165 & 2.02 & $0.080 \times 10^{-2}$ & --- & 0.0308 & 0.0069 \\
\hline 7 & Grid plate & 2.5 & 4.90 & 24.4 & 0.07 & 1.0 & 0.30 & 0.09 & 0.0948 & 1.0538 & 1.41 & $0.284 \times 10^{-2}$ & --- & 0.0150 & 0.0246 \\
\hline 8 & Grid plate & 3.0 & 5.88 & 24.4 & 0.03 & 0.5 & 0.57 & 0.32 & 0.0092 & 0.0284 & 2.68 & $0.090 \times 10^{-2}$ & --- & 0.0542 & 0.0078 \\
\hline 9 & Grid plate & 3.0 & 5.88 & 24.6 & 0.03 & 1.0 & 0.53 & 0.28 & 0.0171 & 0.0610 & 2.49 & $0.017 \times 10^{-2}$ & --- & 0.0469 & 0.0014 \\
\hline 10 & Grid plate & 3.0 & 5.88 & 24.8 & 0.03 & 2.0 & 0.55 & 0.30 & 0.009 & 0.0298 & 2.59 & $0.013 \times 10^{-2}$ & --- & 0.0505 & 0.0013 \\
\hline 11 & Grid plate & 3.0 & 5.88 & 24.4 & 0.05 & 1.0 & 0.50 & 0.25 & --- & --- & 2.35 & $0.067 \times 10^{-2}$ & --- & 0.0417 & --- \\
\hline 12 & Grid plate & 3.0 & 5.88 & 24.4 & 0.05 & 3.0 & 0.50 & 0.25 & --- & --- & 2.35 & $0.029 \times 10^{-2}$ & --- & 0.0417 & --- \\
\hline 13 & Grid plate & 3.0 & 5.88 & 24.4 & 0.07 & 1.0 & 0.42 & 0.18 & 0.1965 & 0.8306 & 1.97 & $0.29 \times 10^{-2}$ & --- & 0.0294 & 0.0259 \\
\hline 14 & Undisturbed & 4.0 & 7.84 & 24.4 & 0.00 & 0.0 & 0.55 & 0.30 & 0.0367 & 0.1216 & 2.58 & $0.011 \times 10^{-2}$ & 1.000 & 0.0505 & 0.0009 \\
\hline 15 & Grid plate & 4.0 & 7.84 & 24.2 & 0.03 & 1.0 & 0.62 & 0.38 & 0.0404 & 0.1052 & 2.91 & $0.015 \times 10^{-2}$ & 1.364 & 0.0641 & 0.0013 \\
\hline 16 & Grid plate & 4.0 & 7.84 & 24.2 & 0.05 & 1.0 & 0.60 & 0.36 & 0.0391 & 0.0957 & 3.01 & $0.107 \times 10^{-2}$ & 9.727 & 0.0683 & 0.0093 \\
\hline 17 & Grid plate & 4.0 & 7.84 & 24.4 & 0.07 & 1.0 & 0.57 & 0.32 & 0.0541 & 0.1667 & 2.68 & $0.280 \times 10^{-2}$ & 25.455 & 0.0542 & 0.0243 \\
\hline
\end{tabular}

---- Not computed, and $q_{u}$ is computed from Test- 14 as $q_{u}=0.011 \times 10^{-2} \mathrm{~cm}^{3} / \mathrm{cm} . \mathrm{s}$ for undisturbed flow. 


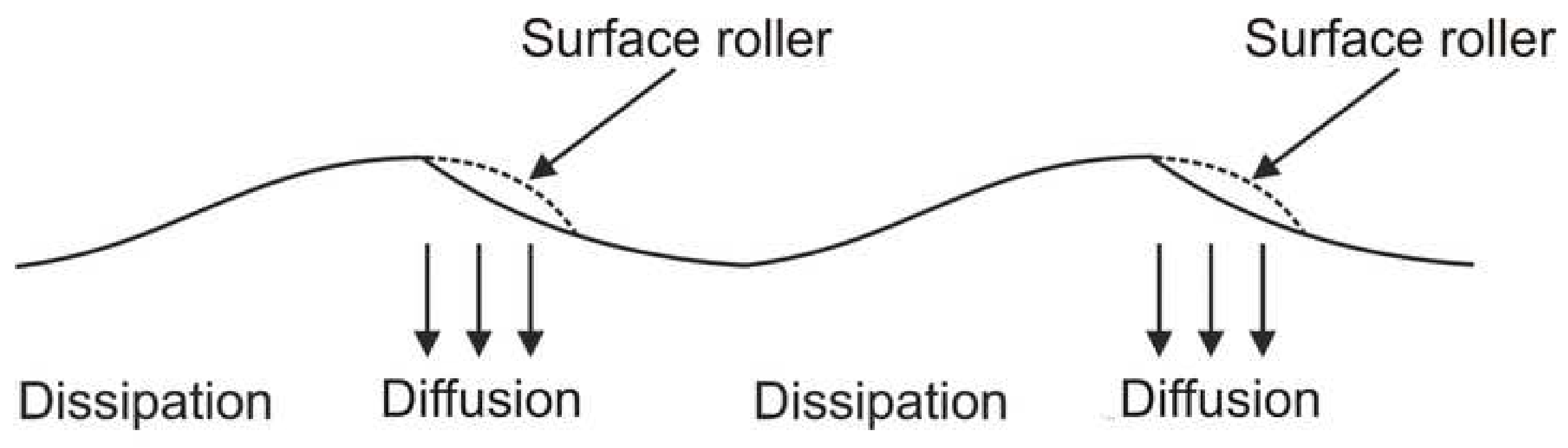

Sediment Bed

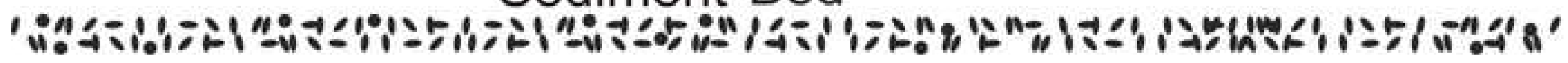




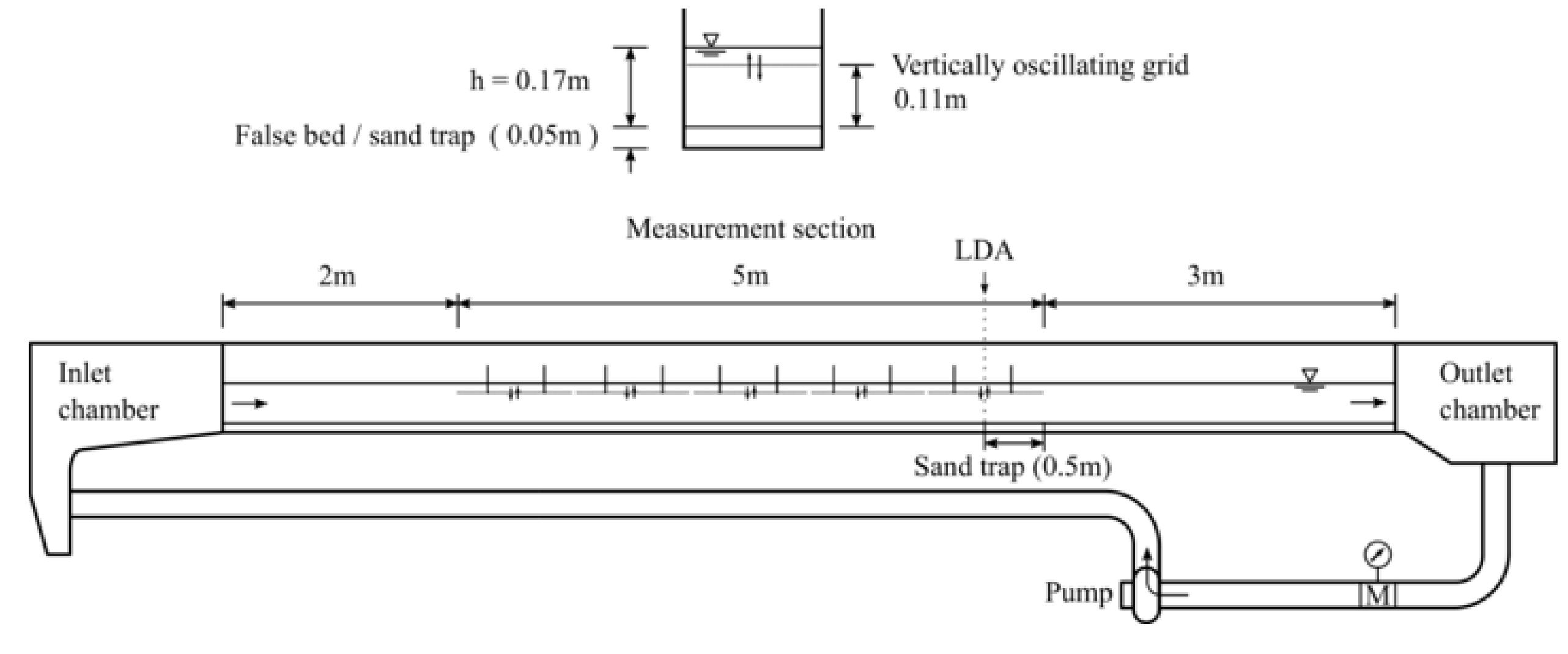



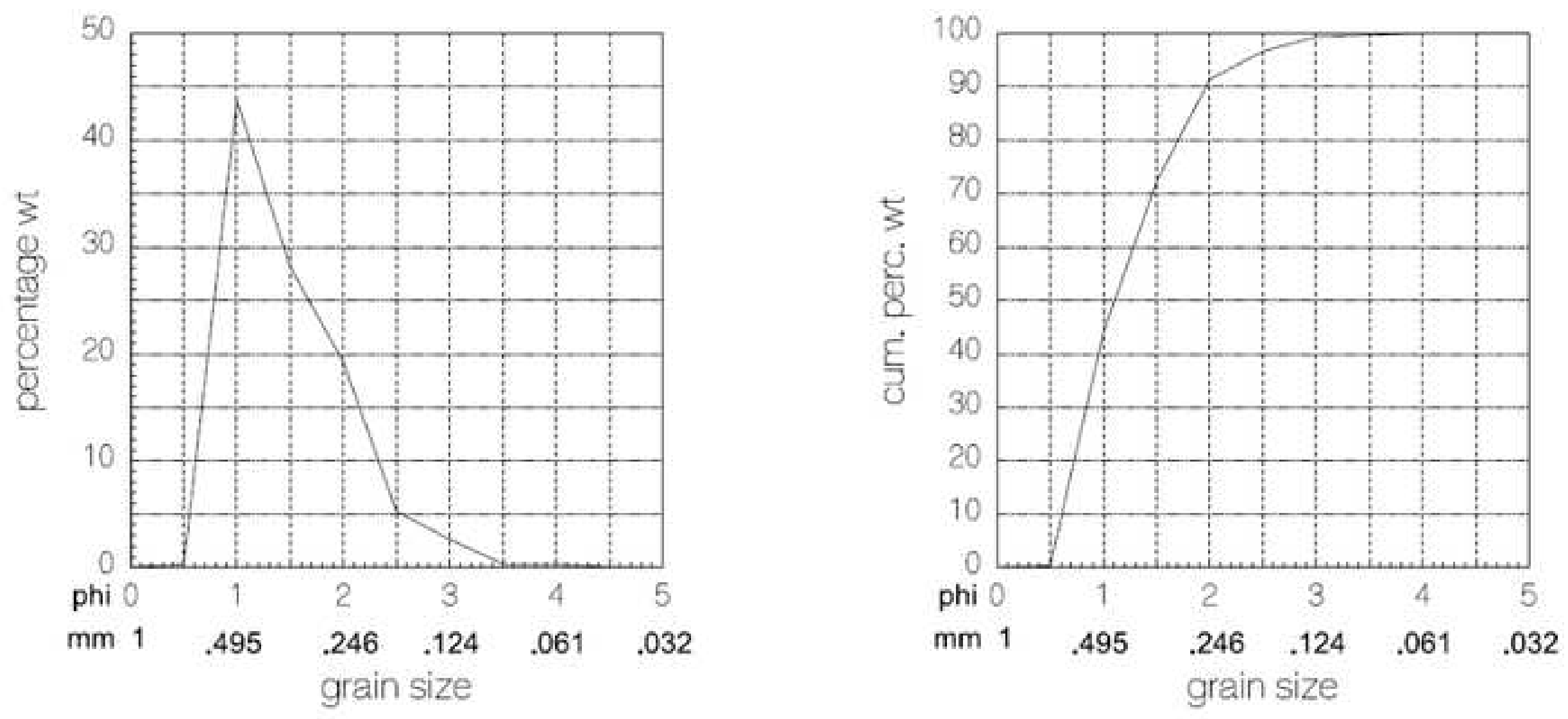


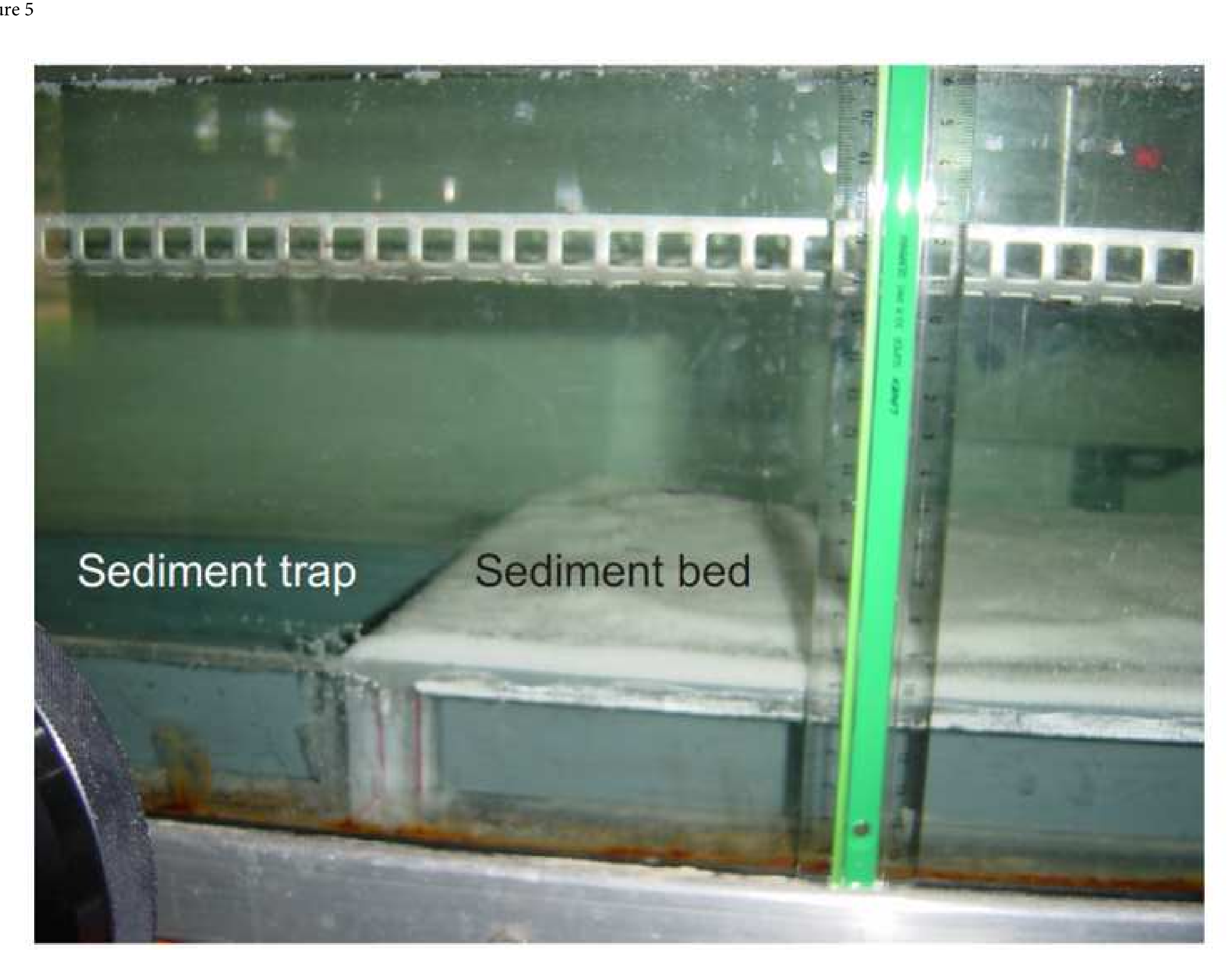

Sediment trap

Sediment bed

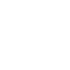

西

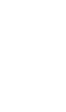



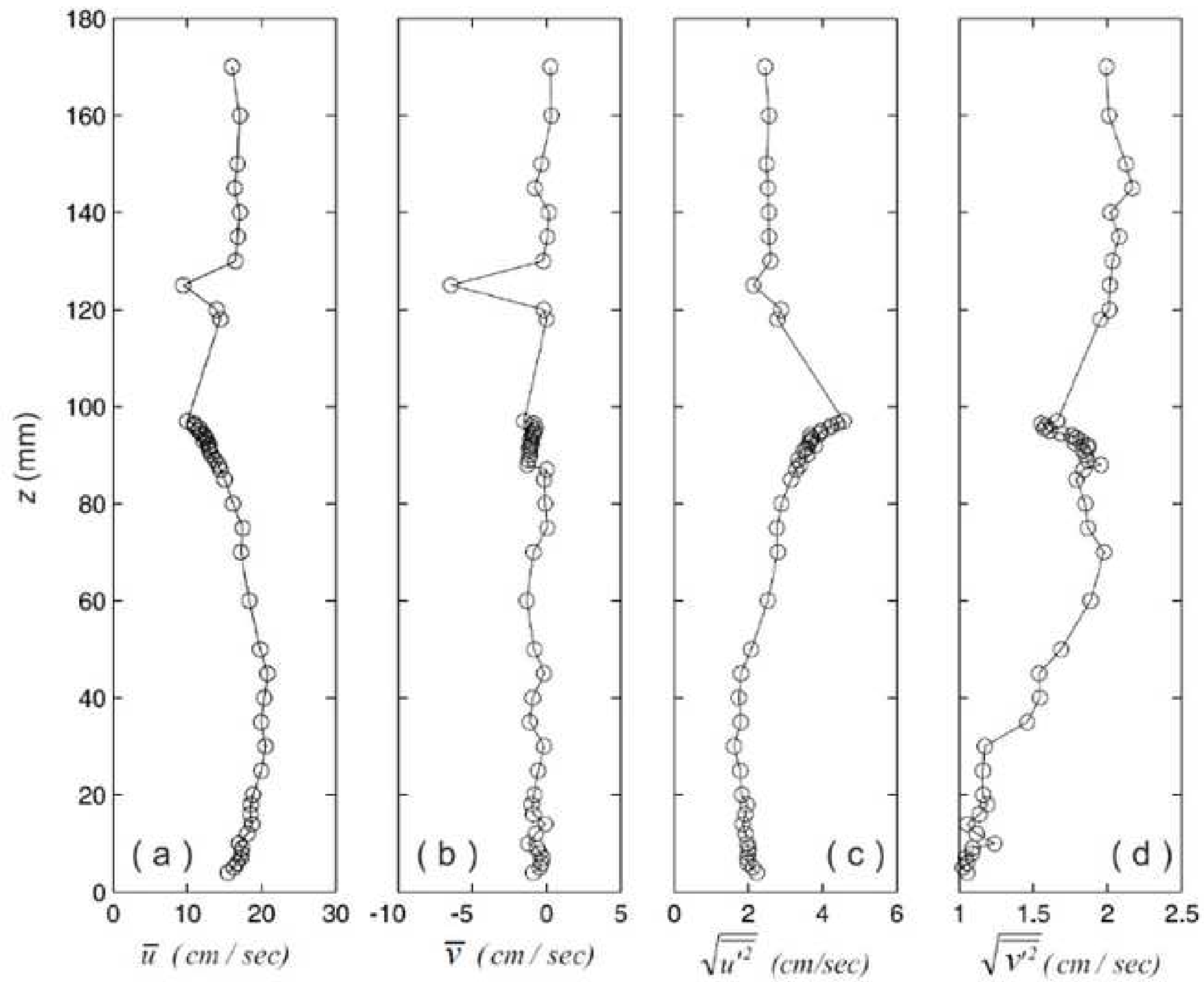

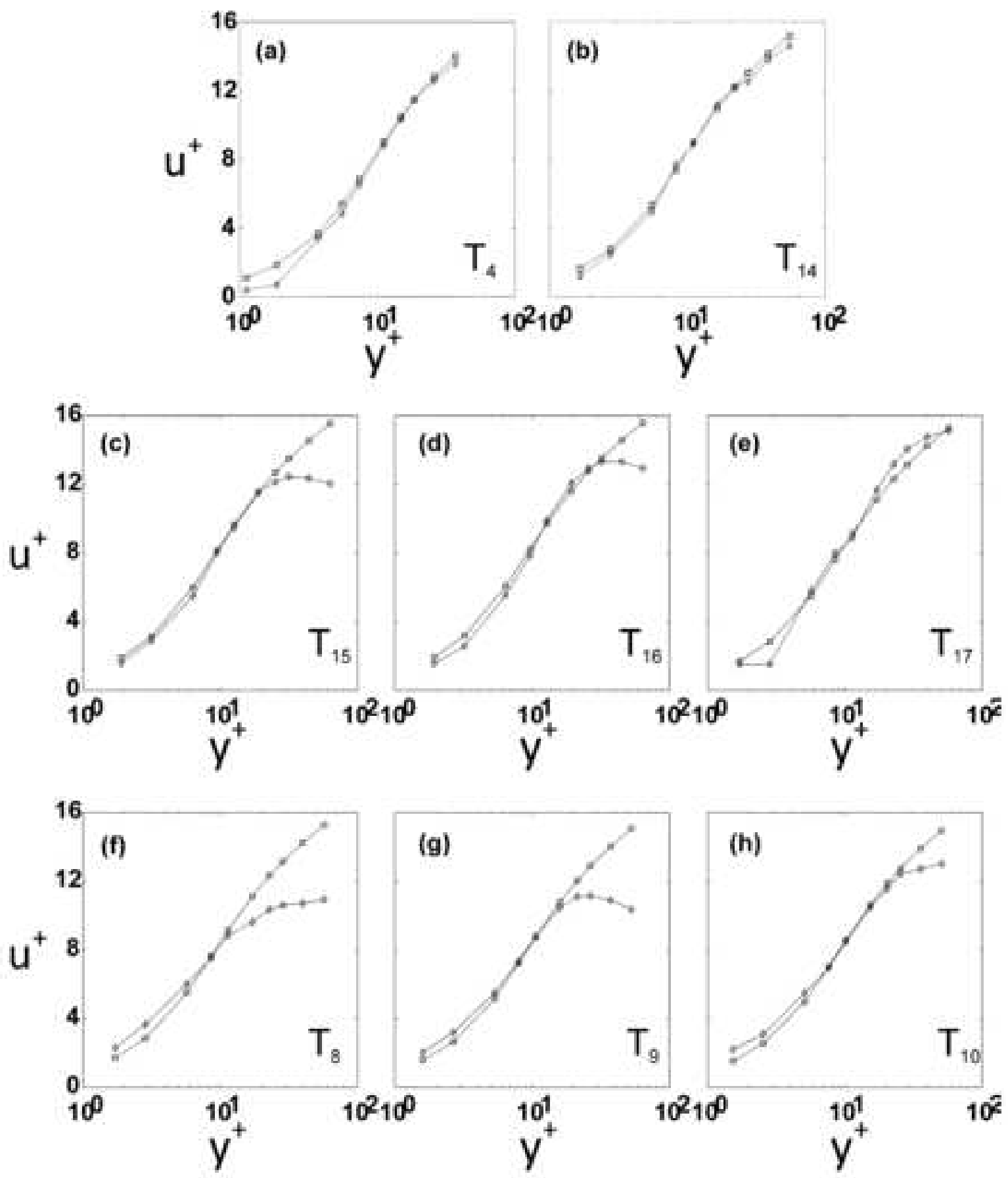

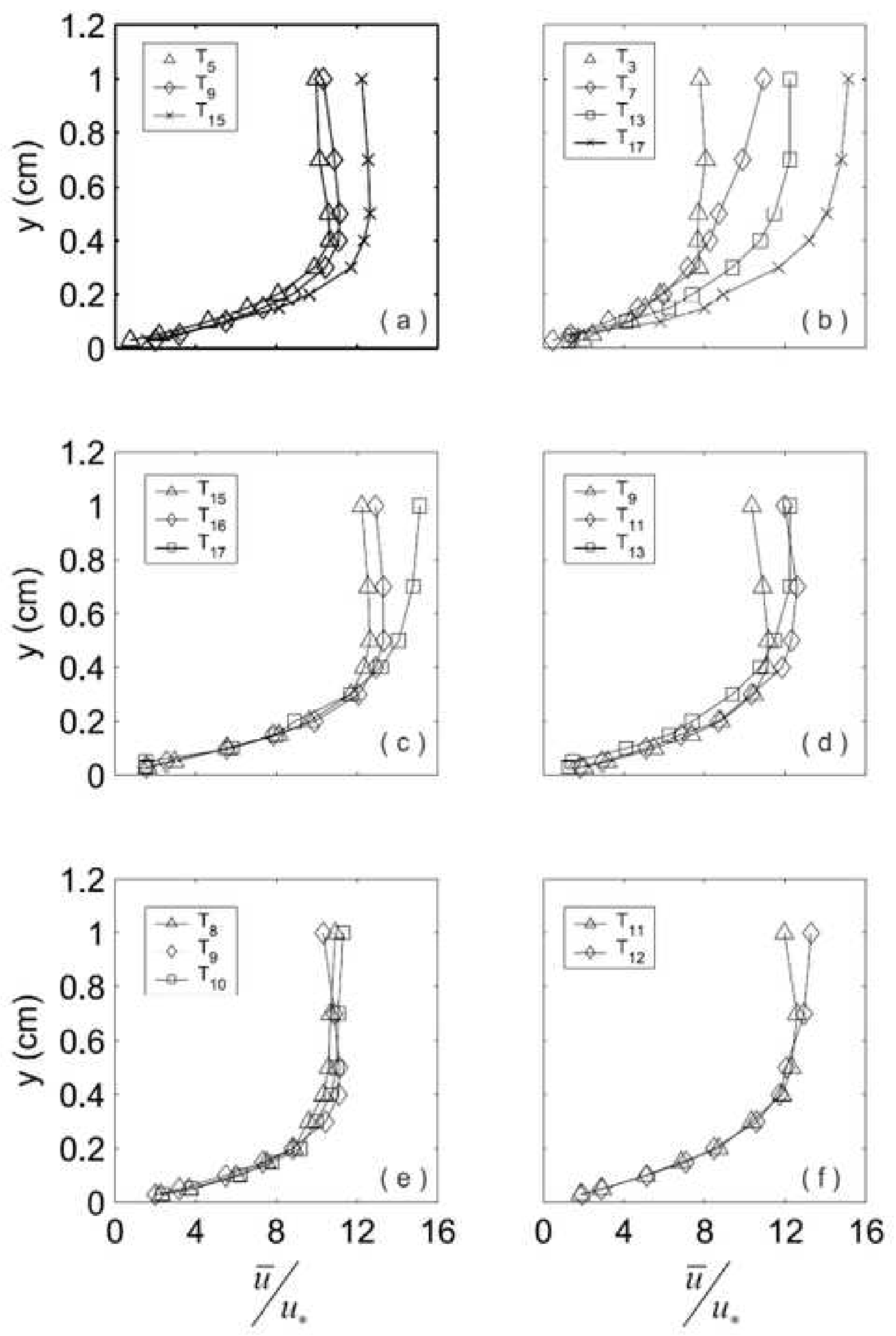

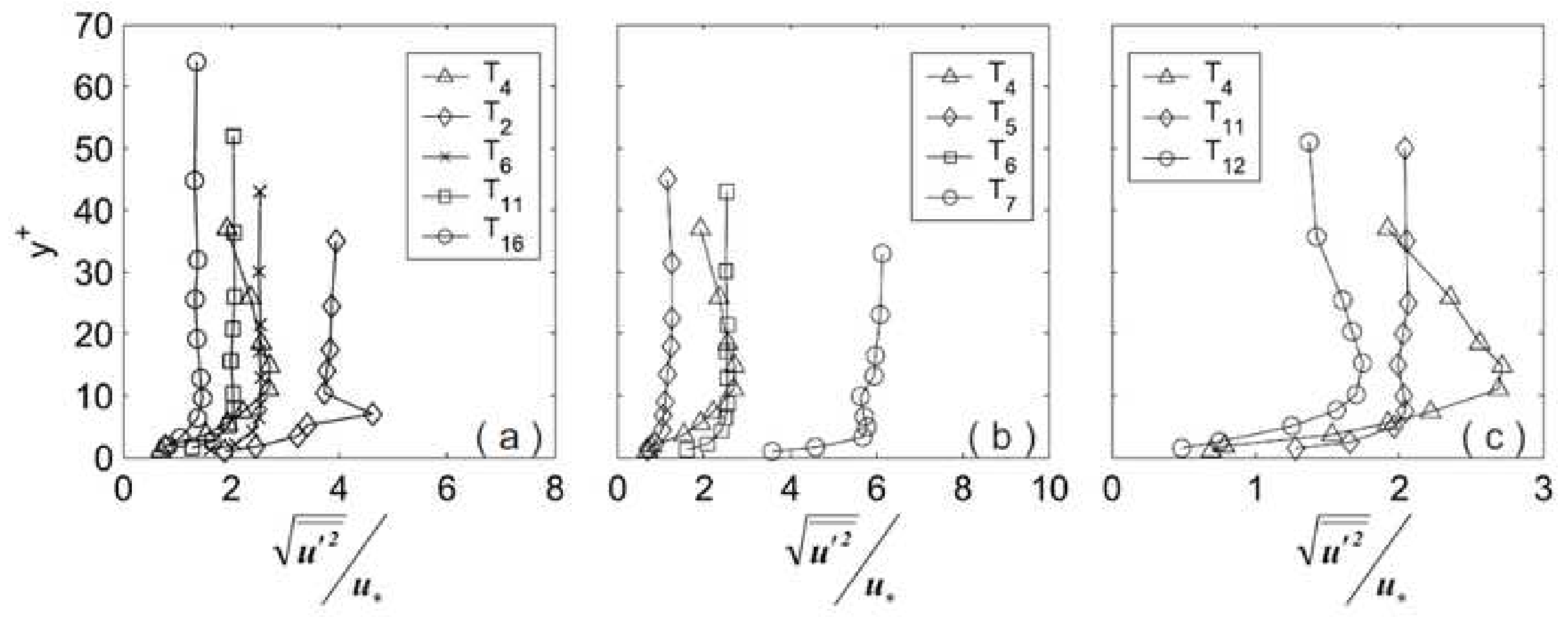

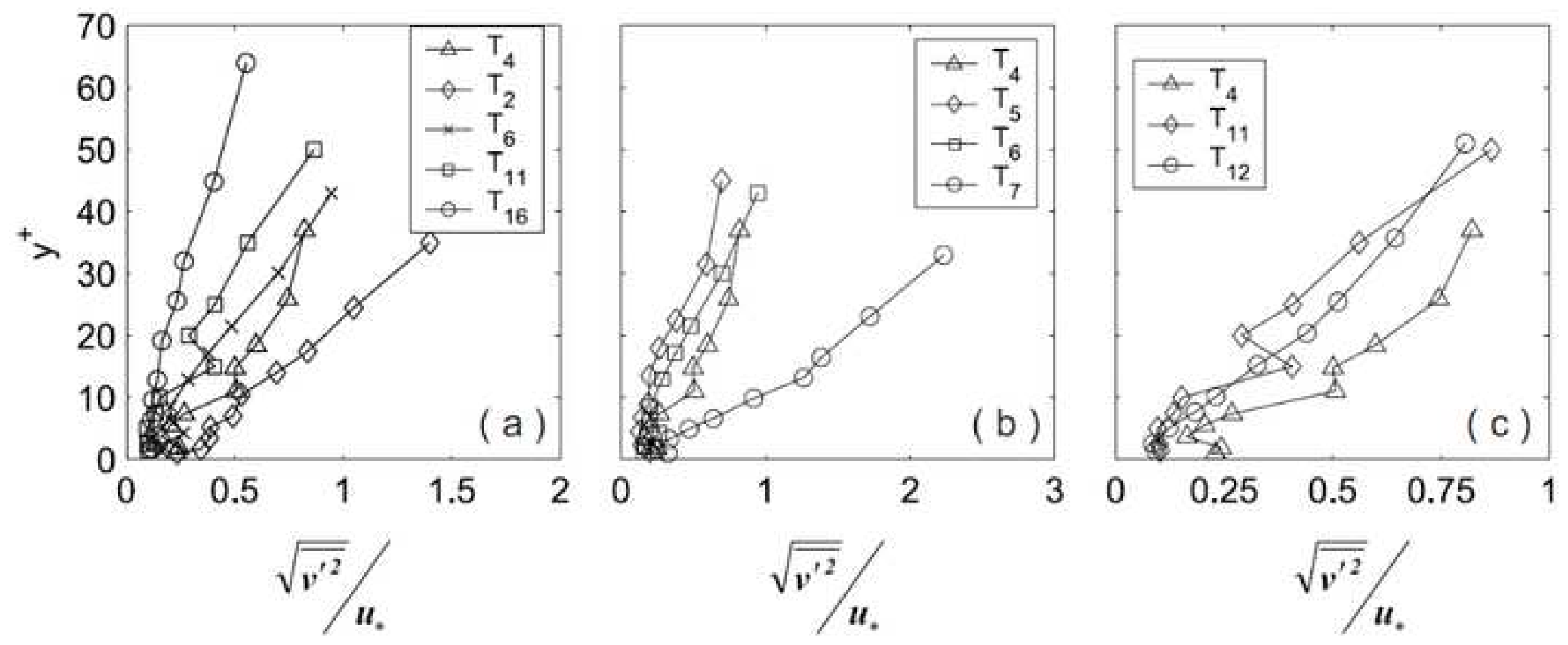


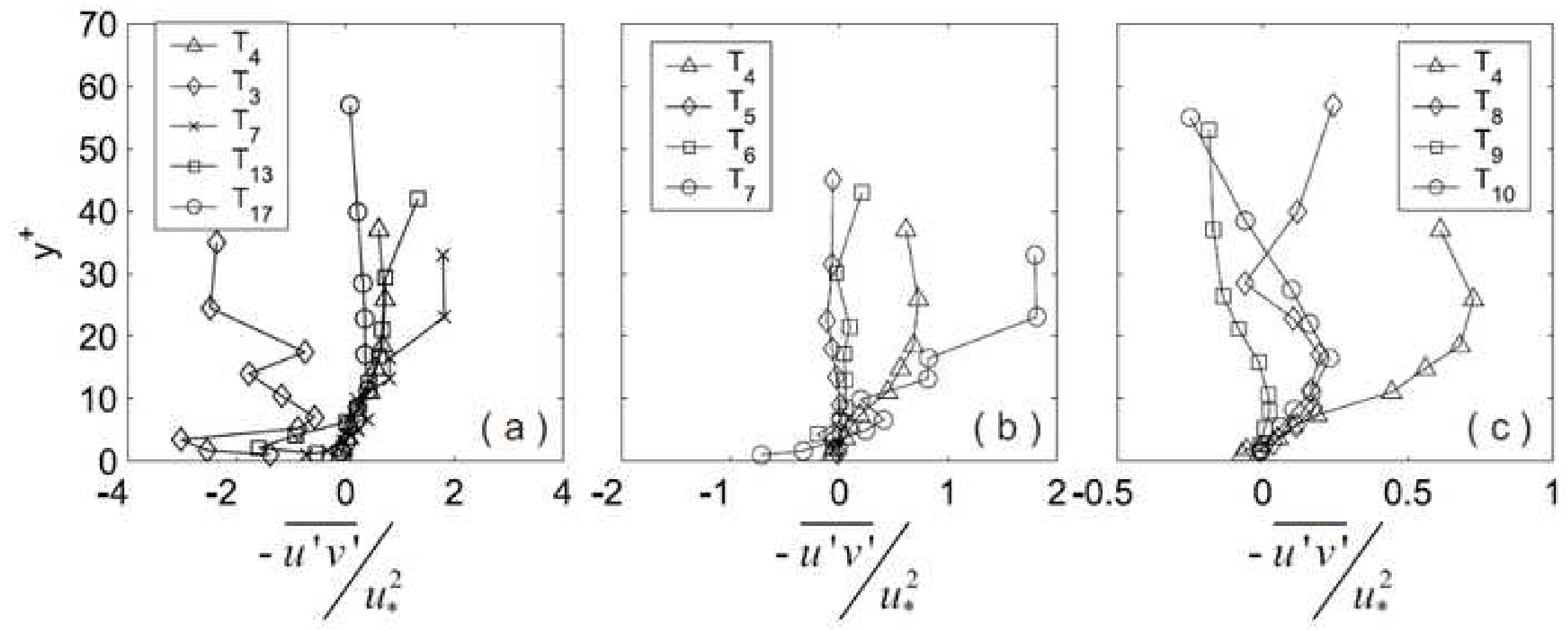



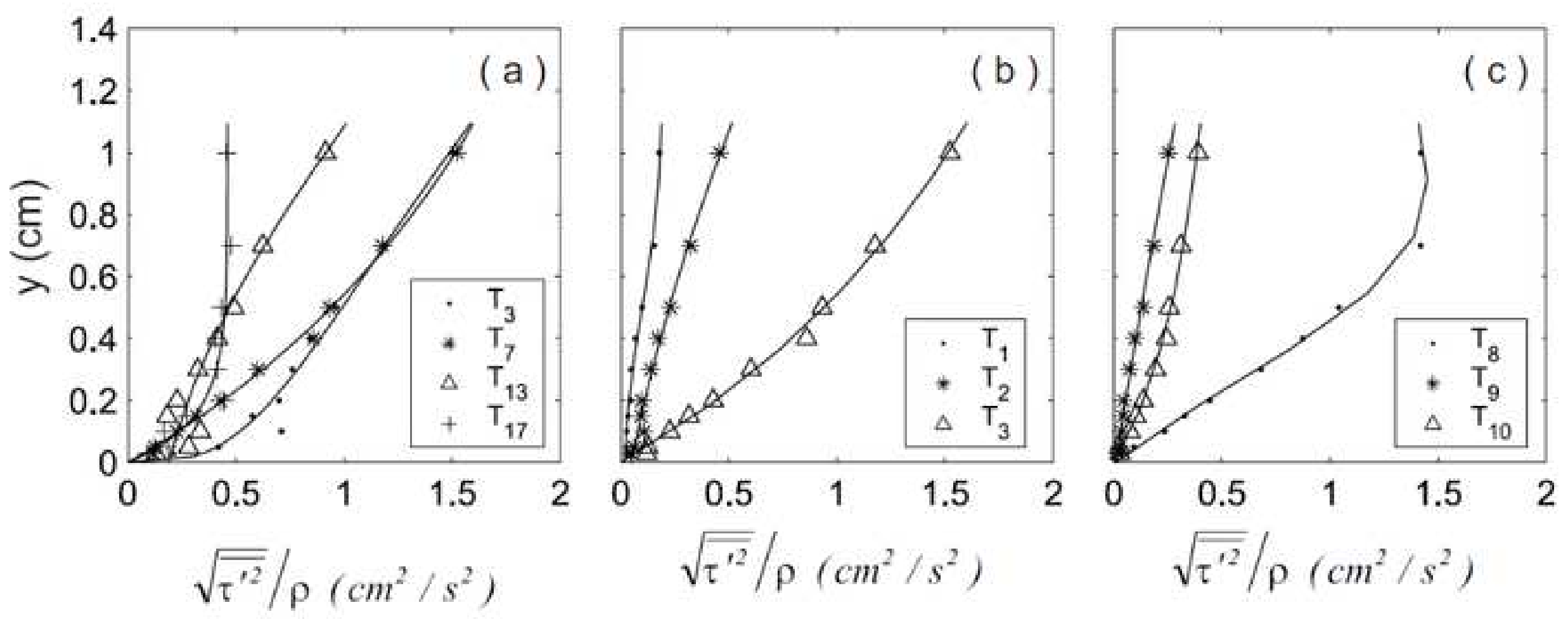
(a) $\mathrm{Y}=0.3 \mathrm{~cm} ; \mathrm{CS}=3 \mathrm{~cm}$

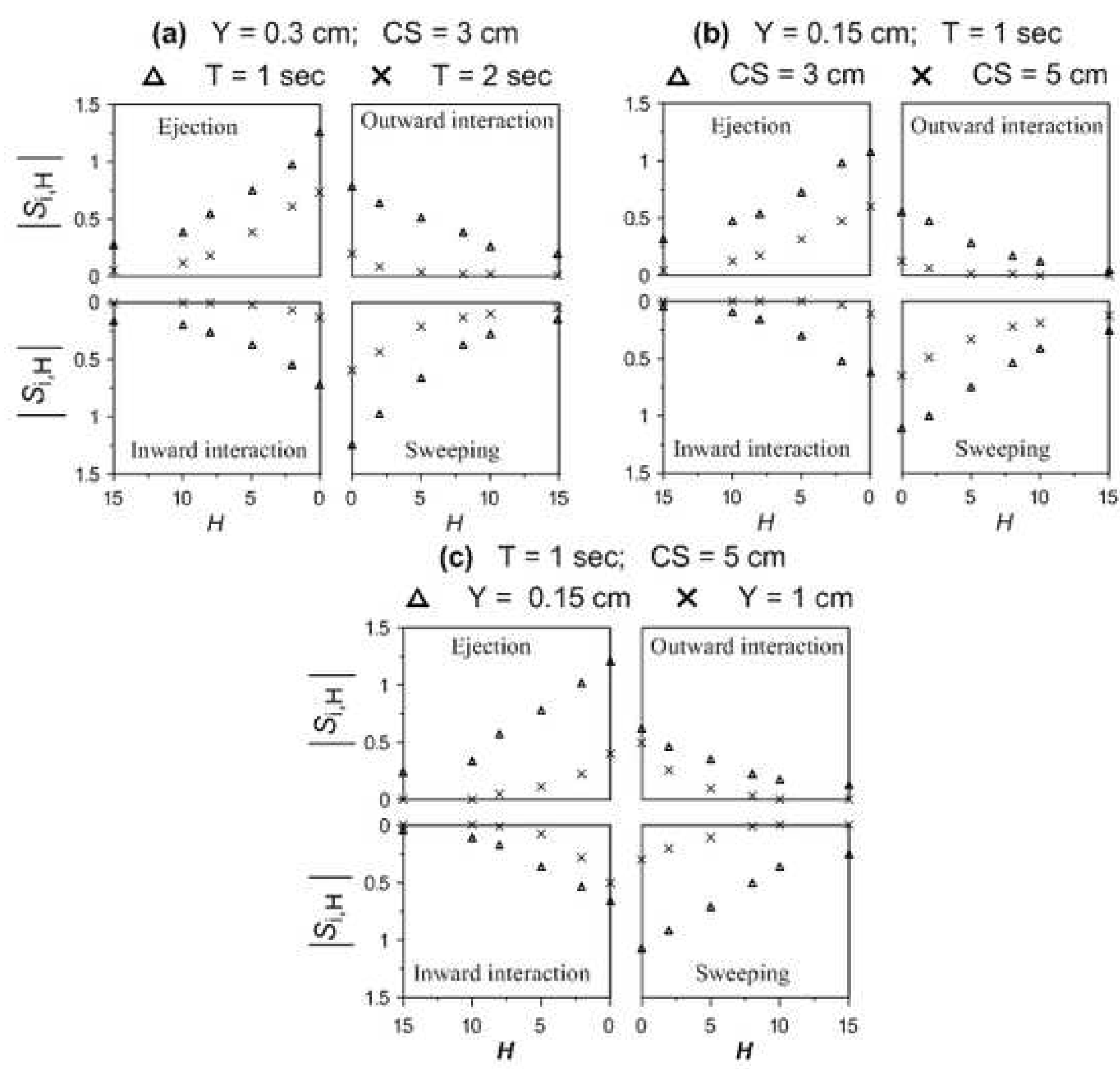

(b) $Y=0.15 \mathrm{~cm} ; T=1 \mathrm{sec}$

(c) $T=1 \mathrm{sec} ; \quad \mathrm{CS}=5 \mathrm{~cm}$
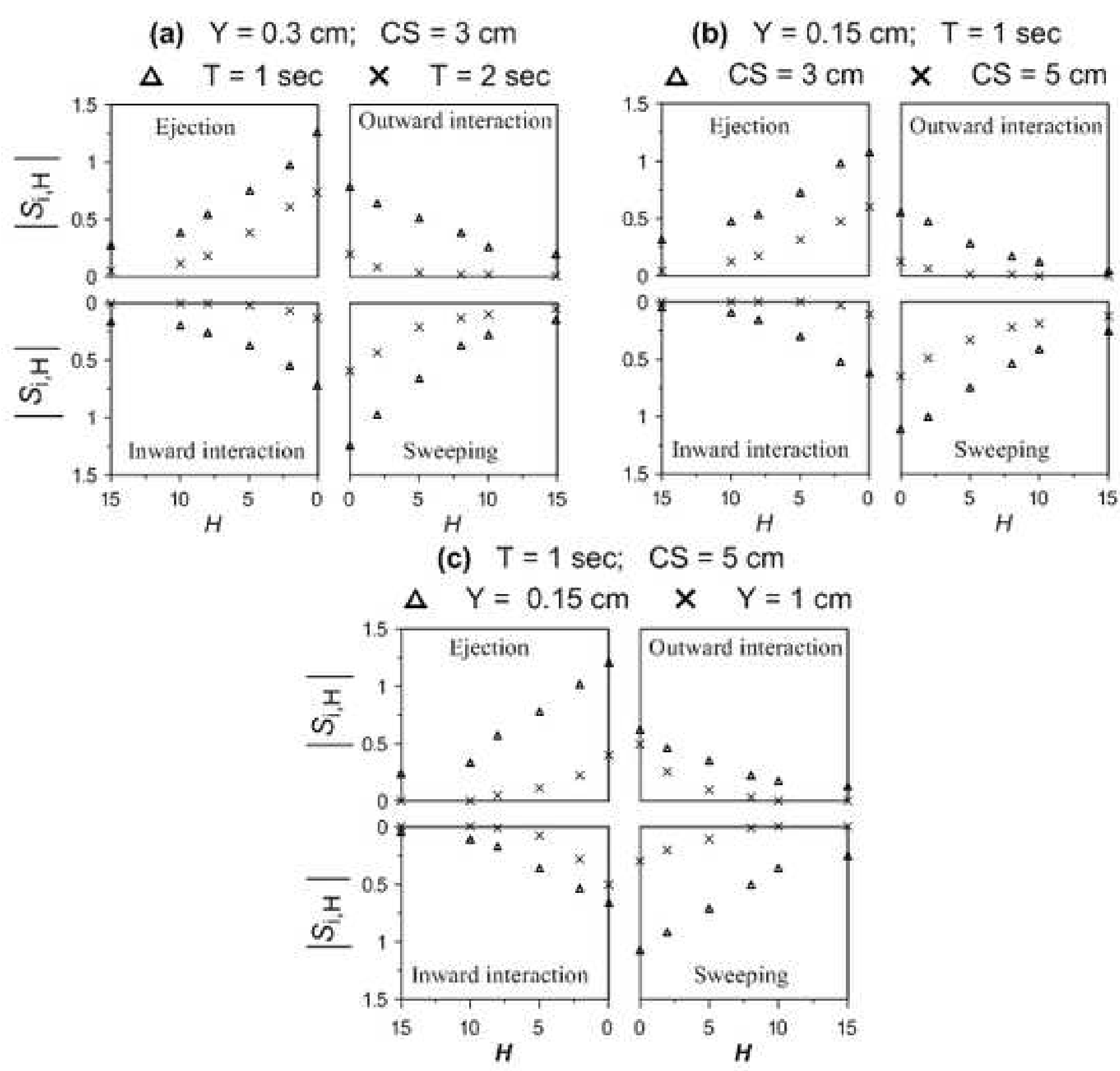

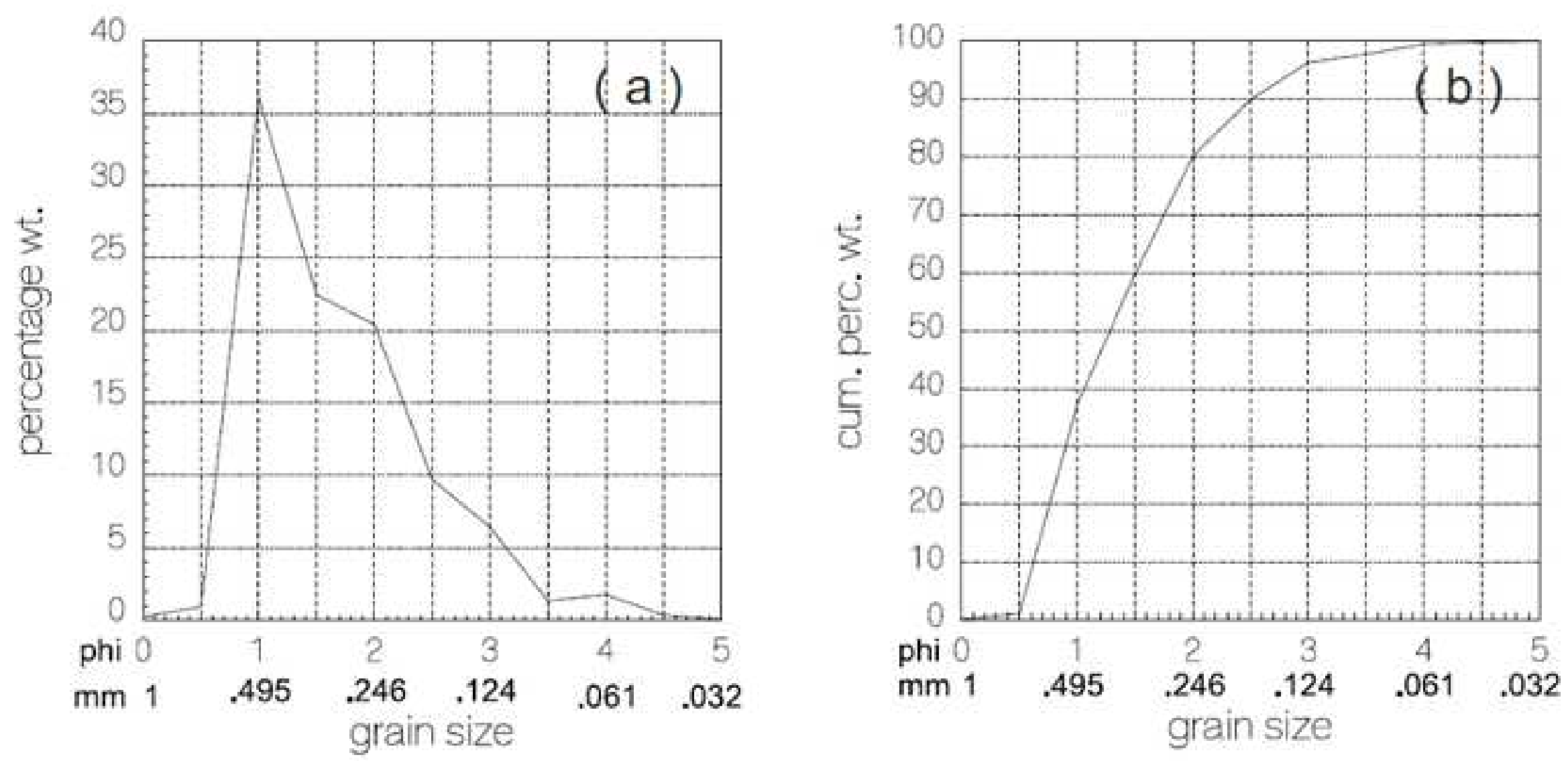


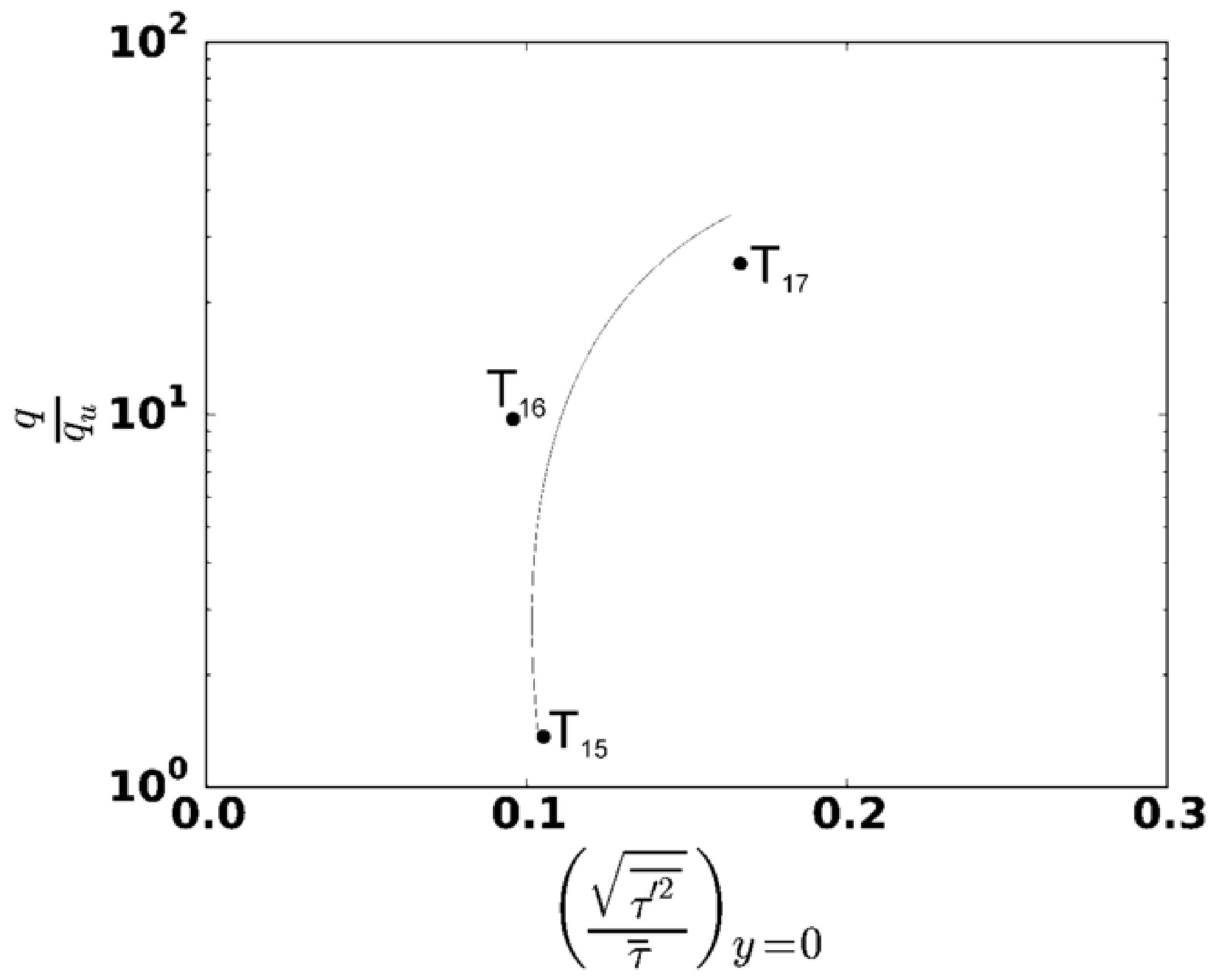




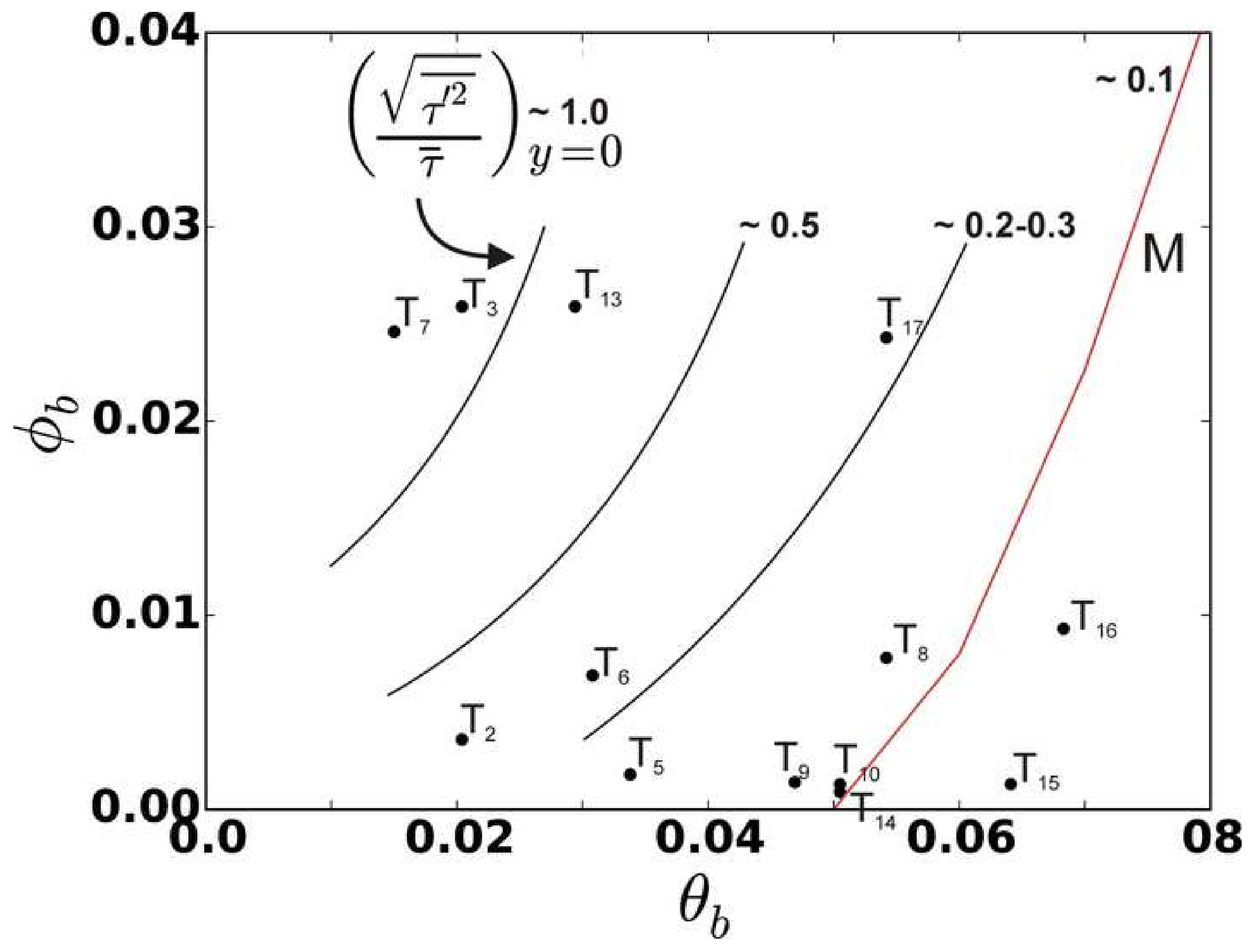




\section{List of Figure Captions}

Figure 1. Sketch of broken waves migrating towards right.

Figure 2. Schematic of the experimental set up with oscillating grid plate and LDV, flow from left to right.

Figure 3. Photograph of experimental setup with LDA at DTU, Denmark. Flow is from right to left.

Figure 4. Grain-size distribution of sand bed: (a) percentage weight and (b) cumulative percentage weight.

Figure 5. Picture of sediment trap together with sediment bed, flowing from right to left.

Figure 6. Mean velocities and turbulence intensities of the undisturbed flow with submerged grid placed at level $110 \mathrm{~mm}$ with a discharge $\mathrm{Q}=10 \mathrm{l} / \mathrm{s}$.

Figure 7. Plots of normalized stream-wise mean velocity profiles along with fitted van-Driest profiles. $\diamond$ : Experimental data, $\square$ : fitted profiles due to van-Driest (1956) for various values of discharge $(Q)$, carriage stroke $(\mathrm{CS}=2 \mathrm{a})$ and period of oscillation $(\mathrm{T})$ of turbulence generator. Test runs $\mathrm{T}_{4}$ and $\mathrm{T}_{14}$ (Figures $7 \mathrm{a}, \mathrm{b}$ ) represent undisturbed flow.

Figure 8. Normalized stream-wise mean velocity profiles against vertical coordinate y for various values of discharge $(Q)$, carriage stroke $(\mathrm{CS}=2 \mathrm{a})$ and period of oscillation $(\mathrm{T})$ of the turbulence generator.

Figure 9. Turbulence intensity profiles along stream-wise direction for various values of discharge $(Q)$, carriage stroke $(\mathrm{CS}=2 \mathrm{a})$ and period of oscillation $(\mathrm{T})$ of turbulence generator.

Figure 10. Turbulence intensity profiles along bottom-normal direction for various values of $Q, \mathrm{CS}$, and T of turbulence generator. Symbols are same as in Figure 9.

Figure 11. Reynolds shear stress profiles against normalized vertical coordinate for various values of $Q$, $\mathrm{CS}$, and $\mathrm{T}$ of turbulence generator.

Figure 12. RMS values of fluctuations in Reynolds shear stress.

Figure 13. Plots of contributions of stress fraction to the Reynolds shear stress against threshold parameter $\mathrm{H}$ for all four quadrant events at a fixed discharge $\mathrm{Q}=3 \mathrm{l} / \mathrm{s}$.

Figure 14. Grain-size distribution of the transported materials in the sediment trap: (a) percentage weight and (b) cumulative percentage weight for undisturbed flow (Test $\mathrm{T}_{14}, \mathrm{Q}=4.0 \mathrm{l} / \mathrm{s}$ ).

Figure 15. Normalized sediment transport rate versus turbulence level in bed shear stress, where $q_{u}=$ $0.011 \times 10^{-2} \mathrm{~cm}^{3} / \mathrm{cm} . \mathrm{s}$ for undisturbed flow (Test $\mathrm{T}_{14}, \mathrm{Q}=4.0 \mathrm{l} / \mathrm{s}$ ) which is used for all tests. 
Figure 16. Plots of dimensionless Shields parameter $\theta_{b}$ versus bed load discharge $\phi_{b}$ for different ranges of $(\sqrt{\bar{\tau}} / \bar{\tau})_{y=\mathrm{c}}$. The test run $\mathrm{T}_{14}$ represents the undisturbed experiments for discharge $\mathrm{Q}=4.0 \mathrm{l} / \mathrm{s}$. Here M: the line from Meyer-Peter \& Muller (1948) formula with $\theta_{c r}=0.05$, (Sumer et al., 2003). 